\title{
Towards understanding the suppressed ENSO activity during mid- Holocene in PMIP2 and PMIP3 simulations
}

\author{
Lin Chen ${ }^{1,2,3} \cdot$ Weipeng Zheng ${ }^{2,4} \cdot$ Pascale Braconnot $^{5}$
}

Received: 16 August 2018 / Accepted: 18 January 2019 / Published online: 7 February 2019

(c) The Author(s) 2019

\begin{abstract}
The mechanisms of El Niño-Southern Oscillation (ENSO) variability change during the mid-Holocene (MH) were investigated through analyzing the model simulations from the Paleoclimate Modelling Intercomparison Project Phases (PMIP) phase-2 and phase-3. The majority of PMIP2 and PMIP3 model simulations show a lower level of ENSO activity in the MH simulation compared to the pre-industrial (PI) simulation, which is qualitatively consistent with that inferred from the paleoclimate proxies. Through employing the Bjerknes stability index, we quantified the dynamic and thermodynamic airsea feedbacks in the PI and MH simulations. The quantitative analyses showed that the reduced ENSO variability in MH arose from the weakening in the thermocline (TH), zonal-advection (ZA) and Ekman (EK) feedback terms. We found that all the weakened TH, ZA, and EK terms are associated with the reduction in the response of anomalous thermocline depth $\left(D^{\prime}\right)$ to the zonal wind stress anomaly $\left(\tau_{x}^{\prime}\right)$ in MH compared to PI. The reduced $D^{\prime}$ response is attributed to the flattened meridional structure of ENSO-related $\tau_{x}^{\prime}$ field in $\mathrm{MH}$, which is linked to the enhanced surface poleward mean meridional current in MH. Among many aspects of the mean state changes under the MH orbital forcing, this study identified that the surface mean meridional current change might be a key factor behind the suppressed ENSO variability in MH. Lastly, through comparing our findings with the ENSO future projection studies, we found that the wind-thermocline feedback is susceptible in a changing climate, which implies that minimizing the uncertainty in the wind-thermocline feedback change may help constrain future ENSO response.
\end{abstract}

Keywords ENSO amplitude change in mid-Holocene $\cdot \mathrm{BJ}$ index $\cdot$ Air-sea feedback · Ocean dynamical processes . Meridional structure change

Electronic supplementary material The online version of this article (https://doi.org/10.1007/s00382-019-04637-z) contains supplementary material, which is available to authorized users.

Lin Chen

chenlin@nuist.edu.cn

$\triangle$ Weipeng Zheng

zhengwp@mail.iap.ac.cn

1 Key Laboratory of Meteorological Disaster, Ministry of Education (KLME)/Joint International Research Laboratory of Climate and Environmental Change (ILCEC)/Collaborative Innovation Center on Forecast and Evaluation of Meteorological Disasters (CIC-FEMD), Nanjing University of Information Science and Technology, Nanjing 210044, China

2 State Key Laboratory of Numerical Modeling for Atmospheric Sciences and Geophysical Fluid Dynamics (LASG), Institute of Atmospheric Physics, Chinese Academy of Sciences, Beijing 100029, China
3 State Key Laboratory of Loess and Quaternary Geology (SKLLQG), Institute of Earth Environment, Chinese Academy of Sciences, Xian 710061, China

4 College of Earth and Planetary Sciences, University of Chinese Academy of Sciences, Beijing 100049, China

5 Laboratoire des Sciences du Climat et de l'Environnement, LSCE/IPSL, CEA-CNRS-UVSQ, Université Paris-Saclay, bât. 714, 91191 Gif-sur-Yvette, France 


\section{Introduction}

As the prominent interannual mode in the Earth climate system, the El Niño-Southern Oscillation (ENSO) exerts great influence on the climate and weather across the globe (e.g., Wallace and Gutzler 1981; Rasmusson and Carpenter 1982; Philander 1990; Feng and Li 2011, 2013). There is widespread concern regarding the potential change in ENSO behaviors under global warming. Yet jury is still out regarding how the ENSO variability would respond to the future warming climate (e.g., Latif and Keenlyside 2009; Collins et al. 2010; Li et al. 2017). Actually, the Earth climate system has responded and is continuing to respond to the varying external climate forcing. Investigating the physical mechanism of the ENSO variability change in the past climate provides an alternative way to understand the ENSO response to the changing climate in future (Braconnot et al. 2012a, b; Harrison et al. 2015).

The climate during the mid-Holocene (hereafter MH; $6 \mathrm{ka}$ BP) offers a unique frame to study the linkage between the changes in ENSO variability and the background mean state. Based on the paleoclimate archives (e.g, the corals, molluscs, ice cores, and seafloor and lake sediments), a number of studies have documented that the level of ENSO variability is lower in $\mathrm{MH}$ than present-day climate (e.g., Tudhope et al. 2001; Cobb et al. 2003; Woodroffe and Gagan 2000; Koutavas and Joanides 2012; Mcgregor et al. 2013; Karamperidou et al. 2015; Emile-Geay et al. 2016; Pausata et al. 2017; White et al. 2018; and many other studies), although few studies (e.g., Cobb et al. 2013) argued that due to the high level of internal variability, it is challenging to discern the ENSO behavior change throughout the Holocene. With the aid of climate models with different complexities, many modeling studies (e.g., Clement et al. 2000; Liu et al. 2000; Kitoh and Murakami 2002; Otto-Bliesner et al. 2003; Brown et al. 2008; Zheng et al. 2008; Chiang et al. 2009; Braconnot et al. 2012; An and Choi 2014; Luan et al. 2012, 2015; Roberts et al. 2014; Emile-Geay et al. 2016; see the review by; Chen et al. 2018; Lu et al. 2018) also presented evidence about the reduction in the ENSO variability in $\mathrm{MH}$ compared to present-day climate, albeit showing a large spread in the level of the reduction among the model simulations.

Although the ENSO activity in MH has been widely studied, there is not a consensus on the interpretation of its reduction. Since the end of twenty century, some pioneering studies (e.g., Bush 1999; Clement et al. 1999, 2000; OttoBliesner 1999; Liu et al. 2000) have conducted modeling simulation to explore the ENSO response to the $\mathrm{MH}$ climate condition. The early work by Clement et al. (2000) suggested that the suppression of ENSO intensity was attributed to the orbital driven changes in the annual cycle over the tropical region in $\mathrm{MH}$. Clement et al. (2000) also pointed out that the model employed in their study was highly idealized, and thus they could not rule out the likelihood that there are some other contributing factors that also played a role in suppressing the ENSO activity in MH. With the aid of a coupled ocean-atmosphere model, Liu et al. (2000) suggested that the reduced ENSO activity in MH was caused by the strengthened Asian summer monsoon and the altered thermocline due to the subduction of warm water from the extratropics to the equatorial thermocline. It was inferred that the reduced ENSO variance might be caused by the nonlinearity associated with frequency entrainment (Liu 2002; Timmermann et al. 2007). Such inference implied an anti-correlation between intensities of the ENSO variability and seasonal cycle; however, other modeling studies argued that both the ENSO and seasonal cycle intensities were reduced during MH (e.g., Braconnot et al. 2012) and the ENSO reconstruction records did not show such inversed relationship (Emile-Geay et al. 2016). Through conducting idealized simulations with an intermediate coupled model, Chiang et al. (2009) found that the aforementioned factors (e.g., the tropical mean state changes associated with the strengthened Asian monsoon, and the frequency entrainment's effect) did not appear to be operating. Rather, they suggested that the MH ENSO variability reduction was induced by the suppression of the atmospheric activity in the North Pacific extratropic region. Using a coupled model with an ensemble of perturbed physics versions, Brown et al. (2008) suggested that the weakened ENSO variability in $\mathrm{MH}$ was associated with the strengthened mean easterly wind in the western and central Pacific equatorial region. Concurrently, Zheng et al. (2008) also suggested that the suppressed ENSO variability in $\mathrm{MH}$ was attributed to the strengthened trade wind in Pacific equatorial region, on the basis of PMIP2 model simulations. Consistently, Luan et al. (2012) found that the reduced ENSO intensity in $\mathrm{MH}$ simulated by a CGCM developed by IPSL arose from the counteractive effect due to the change in the seasonality of the equatorial thermocline depth, and they further linked the altered seasonality of thermocline depth to the enhanced Asian summer monsoon and intensified trade wind. However, these studies have not fully pointed out the key physical processes behind the strengthened equatorial easterly, i.e., how the strengthening in the background mean easterly modulated the interannual variability.

The diversity in the interpretation of the reduced ENSO intensity among the aforementioned modeling studies probably arises from that their conclusions may be modeldependent. This implies that analyzing the modeling results from multi-model simulations may reduce the uncertainty and make the conclusions relatively more credible. Another possibility is that all the aforementioned factors may contribute to the suppression in ENSO intensity in $\mathrm{MH}$; however, the contribution from some factors may be greater while the 
contribution from the other factors may be less. Therefore, it is necessary to refine the interpretations proposed by previous studies and identify the key factors that dominate the reduced ENSO variance in $\mathrm{MH}$.

To achieve this goal, this study intended to reinvestigate the mechanisms of the decrease in ENSO intensity in $\mathrm{MH}$ through analyzing the multi-model simulations derived from PMIP2 (Braconnot et al. 2007a, b) and PMIP3 models (Braconnot et al. 2012a, b; Taylor et al. 2012). To probe the linkage between the background mean state change and ENSO variability in $\mathrm{MH}$, this study intended to quantitatively diagnose the air-sea feedback processes associated with ENSO intensity in the MH and PI simulations. This is because many ENSO studies have suggested that the ENSO variability is determined by the dynamic and thermodynamic air-sea feedback processes (e.g., Jin et al. 2006; Li 1997; Bellenger et al. 2014; Li et al. 2015, 2017). Understanding the key airsea feedbacks responsible for the ENSO variability change could help bridge the gap between the background mean state change and interannual variability change.

The remainder of the paper is organized as follows: we outline the models, the experiment design, and the $\mathrm{BJ}$ index used in the study in Sect. 2; we present the changes in the ENSO variability in Sect. 3; we then explore the dominant air-sea feedback processes responsible for the MH ENSO variability change in Sect. 4; lastly, a summary is given in Sect. 5 and a discussion is provided in Sect. 6.

\section{Model, experiments, and method}

\subsection{PMIP models and the experiments}

The model outputs utilized in this study were taken from 28 CGCMs, including 15 PMIP2 models and 13 PMIP3 models. According to the experiment protocol of PMIP2 and PMIP3, two suites of experiments were mainly investigated in this study. The first is the pre-industry simulation (hereafter PI), which was employed to represent the modern-day climate, and the second is the MH simulation. In the $\mathrm{MH}$ simulation, the topography and ice sheets were the same as those set for the PI simulation. The concentrations of greenhouse gases set for MH simulation was also the same as those prescribed for the PI simulation, except that $\mathrm{CH}_{4}$ was changed from 760 to $650 \mathrm{ppb}$. The major difference of the forcing and boundary conditions between the two simulations lies in the difference in the orbital parameters: the eccentricity is $0.0167724(0.018682)$ in PI $(\mathrm{MH})$, the obliquity is $23.446^{\circ}\left(24.105^{\circ}\right)$ in PI (MH), and the angular precession is $102.04^{\circ}\left(0.87^{\circ}\right)$ in PI (MH). For more details about the PMIP models and the experiment design, please refer to Braconnot et al. (2007a, b), Taylor et al. (2012), or/ and the introduction in the website of http://pmip3.1sce.ipsl. fr/. In this study, the last 100 years' monthly datasets from the PMIP2 and PMIP3 models were utilized, and all the interannual anomaly fields were obtained through removing the climatological annual cycle from the raw monthly datasets. It is worth mentioning that the analyses associated with the quantitative diagnoses of air-sea feedback processes are conducted based on 11 PMIP3 models. This is because the PMIP2 outputs only provided the annual mean cycle for three-dimensional oceanic variables while the monthly resolution variables were needed when calculating the air-sea feedbacks, and two PMIP3 models (say, CSIRO-Mk3L-1-2 and EC-EARTH-2-2) did not provide the whole required fields.

\subsection{BJ index}

Based on the recharge oscillator framework (Jin 1997), Jin et al. (2006) developed a simple tool which is termed as the Bjerknes stability index (BJ index), for analyzing the ENSOrelated thermodynamic and oceanic dynamic processes in coupled models. Building on the framework in Jin et al. (2006), Kim and Jin (2011a, b) further completed the tool of BJ index. Recently, the BJ index has been widely used to study the scientific issues associated with the ENSO variability change (e.g., Kim et al. 2014a, b; Liu et al. 2014; Chen et al. 2016a, b; Lu et al. 2016; Zhu et al. 2017; Chen et al. 2018; Wang et al. 2018). Following Kim and Jin (2011a, b), the specific formulations of BJ index employed in this study are shown below:

$\mathrm{BJ}=\frac{R-\varepsilon}{2}$

$$
\begin{aligned}
R= & -\underbrace{\left(a_{1} \frac{\langle\Delta \bar{u}\rangle_{E}}{L_{x}}+a_{2} \frac{\langle\Delta \bar{v}\rangle_{E}}{L_{y}}\right)}_{\mathrm{MA}}-\underbrace{\alpha_{s}}_{\mathrm{TD}}+\underbrace{\mu_{a} \beta_{u}\left\langle-\frac{\partial \bar{T}}{\partial x}\right\rangle_{E}}_{\mathrm{ZA}} \\
& +\underbrace{\mu_{a} \beta_{w}\left\langle-\frac{\partial \bar{T}}{\partial z}\right\rangle_{E}}_{\mathrm{EK}}+\underbrace{\mu_{a} \beta_{h} a_{h}\left\langle\overline{\bar{w}} \frac{\left.\overline{H_{1}}\right\rangle_{E}}{E}\right.}_{\mathrm{TH}}
\end{aligned}
$$

$\frac{\partial\langle h\rangle_{w}}{\partial t}=-\varepsilon\langle h\rangle_{w}-\widetilde{F}\left[\tau_{x}\right]$

$\langle\mathrm{Q}\rangle_{E}=-\alpha_{s}\langle T\rangle_{E}$

$\left[\tau_{x}\right]=\mu_{a}\langle T\rangle_{E}$

$\langle h\rangle_{E}-\langle h\rangle_{W}=\beta_{h}\left[\tau_{x}\right]$

$\left\langle\mathrm{H}(\bar{w}) T_{\text {sub }}\right\rangle_{E}=a_{h}\langle h\rangle_{E}$

$\langle u\rangle_{E}=\beta_{u}\left[\tau_{x}\right]+\beta_{u h}\langle h\rangle_{w}$ 


$$
\langle\mathrm{H}(\bar{w}) w\rangle_{E}=-\beta_{w}\left[\tau_{x}\right]
$$

where Eq. (1) depicts the BJ index, which measured the ENSO's growth rate discussed in this study; Eq. (2) describes the corresponding dynamic and thermodynamic feedbacks; and Eq. (3) denotes the heat content recharge/ discharge process. In particular, the overbar denotes the climatological annual mean, $T$ represents the ocean temperature anomaly and $(u, v, w)$ denote the oceanic current anomalies. Here, the anomaly fields (e.g., $u, v, w$ and $T$ ) are obtained through removing their corresponding climatological annual cycle. \langle\rangle$_{E}$ and \langle\rangle$_{w}$ denote the volume integration above the mixed layer depth $\left(H_{1}\right)$ in the eastern and western boxes, respectively. $L_{x}$ and $L_{y}$ are the longitudinal and latitudinal lengths of the eastern box, respectively. $a_{1}$ and $a_{2}$ are obtained by linear regression using mixed layer temperature anomalies zonally or meridionally averaged at the eastern box boundaries and area-averaged temperature anomalies over the eastern box. $\mathrm{H}(\bar{w})=\left\{\begin{array}{l}1, \bar{w}>0 \\ 0, \bar{w} \leqslant 0\end{array}\right.$ is a step function to guarantee only upward vertical motion is considered. $\Delta$ in Eq. (2) represents the ocean current change between two boundaries; and [] in the $\mathrm{BJ}$ index denotes the anomaly averaged across the entire equatorial Pacific basin. From Eq. (4) to Eq. (9), $\alpha_{s}$ indicates the response of the thermodynamic damping to the sea surface temperature anomalies (SSTAs), $\rho$ and $C_{p}$ denotes the density of seawater and the specific heat capacity, respectively; $\mu_{a}$ represents the response of zonal wind stress anomaly $\left(\tau_{x}^{\prime}\right)$ to SSTAs; $\beta_{h}$ denotes anomalous zonal slope of the equatorial thermocline adjusting to $\tau_{x}^{\prime} ; a_{h}$ represents the impact of thermocline depth change on anomalous ocean subsurface temperature; $\beta_{u}$ indicates the response of upper-ocean zonal current anomaly to $\tau_{x}^{\prime}$; and $\beta_{w}$ indicates a response of anomalous upwelling to $\tau_{x}^{\prime}$.

The factor $R$ in formula (2) collectively represents the five main contributing terms of BJ index, which will be mainly analyzed in this study. For convenience, the abbreviation of these five terms are marked beneath formula 2; from left to right, they comprise two negative feedbacks [i.e., the dynamic damping by the mean advection (MA term; $\left.-\left(a_{1} \frac{\langle\Delta \bar{u}\rangle_{E}}{L_{x}}+a_{2} \frac{\langle\Delta \bar{v}\rangle_{E}}{L y}\right)\right)$ and the thermodynamic damping feedback (TD term; $-\alpha_{s}$ )] and three positive feedbacks [i.e., the zonal advection feedback (ZA term; $\mu_{a} \beta_{u}\left\langle-\frac{\partial \bar{T}}{\partial x}\right\rangle_{E}$ ), Ekman feedback (EK term; $\mu_{a} \beta_{w}\left\langle-\frac{\partial \bar{T}}{\partial z}\right\rangle_{E}$ ) and thermocline feedback (TH term; $\mu_{a} \beta_{h} a_{h}\left\langle\frac{\bar{w}}{H}\right\rangle_{E}$ )]. The two negative feedbacks act to dampen the SST perturbation's increase, while the positive feedbacks favor the SST perturbation's increase. For more detailed description about the BJ index, please refer to Kim et al. (2011a, b).

In this study, we chose the commonly-used broad eastern box $\left(180^{\circ}-80^{\circ} \mathrm{W}, 5^{\circ} \mathrm{S}-5^{\circ} \mathrm{N}\right)$ when calculating the $\mathrm{BJ}$ index, in a similar manner to that applied by some recent studies (Liu et al. 2014; Lübbecke and McPhaden 2014; Lu et al. 2016; Hua et al. 2018), because such a broad eastern box generally contains the core region of ENSO variability, despite of location differences in the maximum center of ENSO intensity change among the models. It is worth mentioning that in the broad eastern box, the direction of the change in ENSO variability is consistent in the majority of the model simulations, which will be described more in the following section. Note that the main conclusions in the present study are not sensitive to a slight change in longitudinal boundaries of the box.

\section{ENSO variability change in MH compared to $\mathbf{P I}$}

Figure 1 shows the spatial pattern of the changes in the standard deviation (STD) of SSTA from the 13 PMIP3 model simulations (Fig. 1a-m) and 15 PMIP2 model simulations (Fig. 1n-ab). Note that the change denotes the difference between PI and $\mathrm{MH}$ (MH minus PI) throughout the remaining paper. It is found that most of the PMIP3 models (10 out of 13) and most of the PMIP2 models (13 out of $15)$ show a decrease in the SSTA variability over the eastern Pacific, although the level of the decrease varies greatly across the model simulations. As clearly shown in the multimodel ensemble (MME) result (Fig. 1ac), the SSTA variability become weakened in the eastern equatorial Pacific, indicating that the simulated ENSO intensity is reduced in $\mathrm{MH}$ relative to PI. Furthermore, we added the dots in Fig. 1ac to show the specific area where the change in ENSO intensity goes to the same direction in more than $75 \%$ of the models. As indicated by the dotted areas, the consistent direction in terms of ENSO intensity change mainly locates in the broad eastern equatorial Pacific, indicating the majority of the models shows an agreement in the simulation of reduced ENSO intensity in MH. The suppressed ENSO intensity simulated by the majority of the PMIP2 and PMIP3 models naturally raises a question, are there any common contributing factors responsible for the suppressed ENSO intensity?

\section{Dominant air-sea feedback processes for the reduced ENSO variability in MH}

\subsection{Changes in $B J$ index in MH and its relationship with ENSO variability change}

Since ENSO growth involves various air-sea feedback processes, it is necessary to firstly shed light on the key air-sea feedback processes contributing to the suppressed ENSO variability in MH compared to PI. We first calculated the $\mathrm{BJ}$ index for the PI and MH simulations from 11 PMIP3 
(a) BCC-CSM1-1

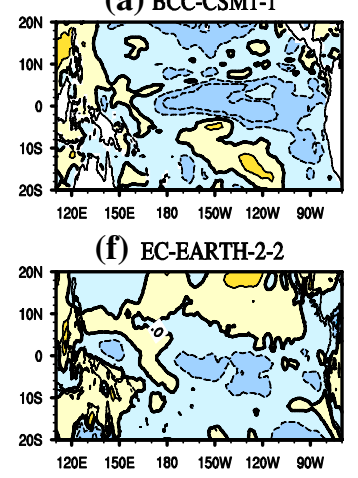

(k) MIROC-ESM

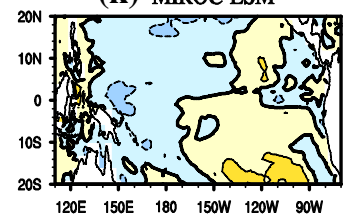

(p) CSIRO-Mk3L-1.1

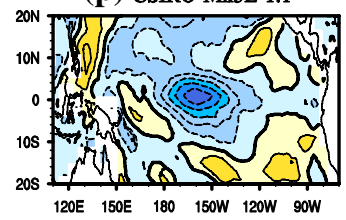

(u) IPSL-CM4-V1-MR

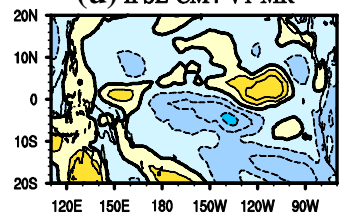

(z) FOAM-oav

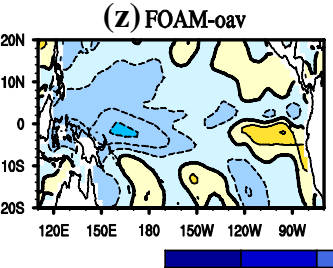

$-0.4 \quad-0.35$ (b) CCSM 4

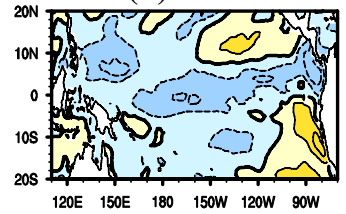

(g) FGOALS-g2

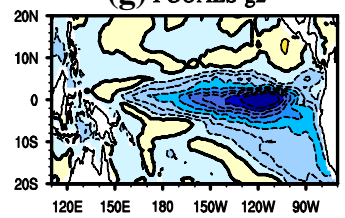

(l) MPI-ESM-P

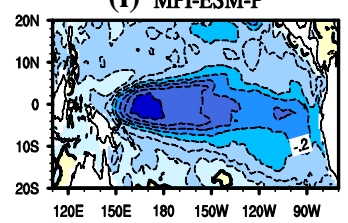

(q) ECBILTCLIOVECODE

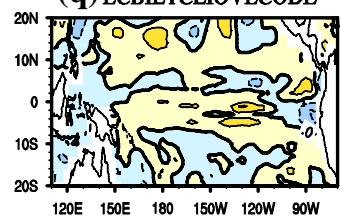

(v) MIROC3.2

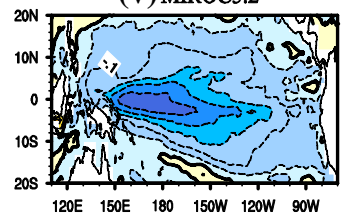

(aa) MRI-CGCM2.3.4fa-oav

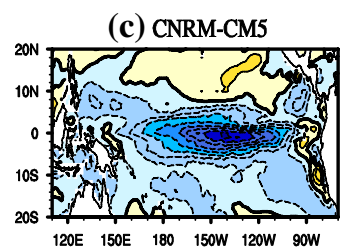

(h) HadGEM2-CC

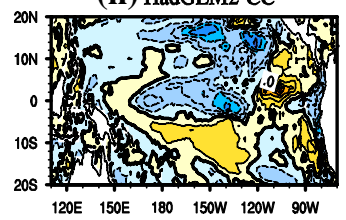

(m) MRI-CGCM3

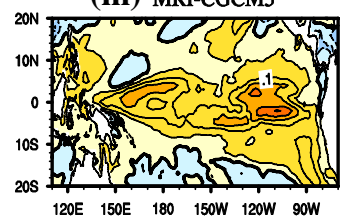

(r) FGOALS-1.0g

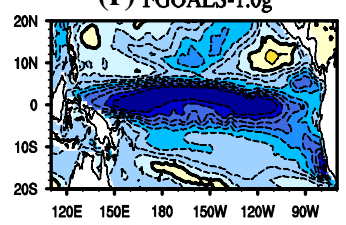

(w) MRI-CGCM2.3.4fa

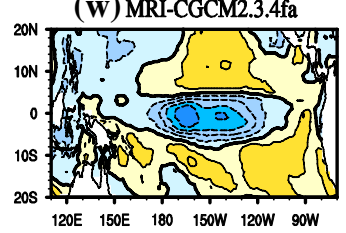

(ab) MRI-CGCM2.3.4nfa-oav

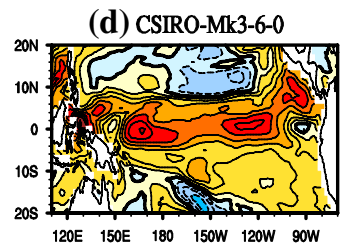

(i) HadGEM2-ES

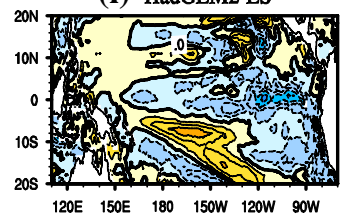

(n) $\mathrm{CCSM}$

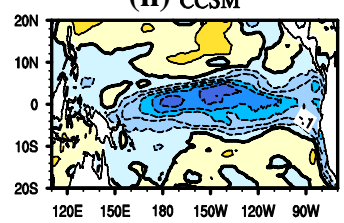

(s) FOAM

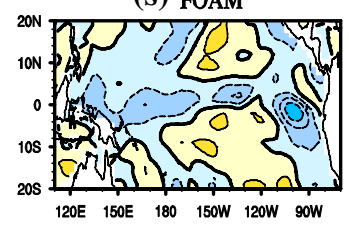

(x)MRI-CGCM2.3.4nfa
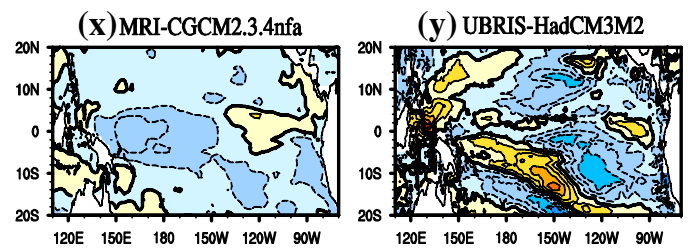

(ac)Ensemble

(e) CSIRO-Mk3L-1-2

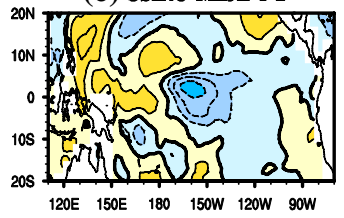

(j) IPSL-CM5A-LR

(o) CSIRO-Mk3L-1.0

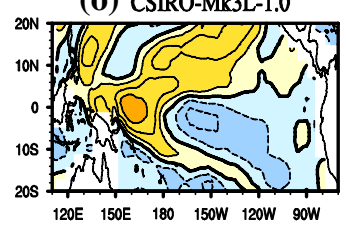

(t) GISSmodelE

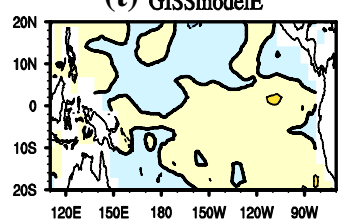

(y) UBRIS-HadCM3M2
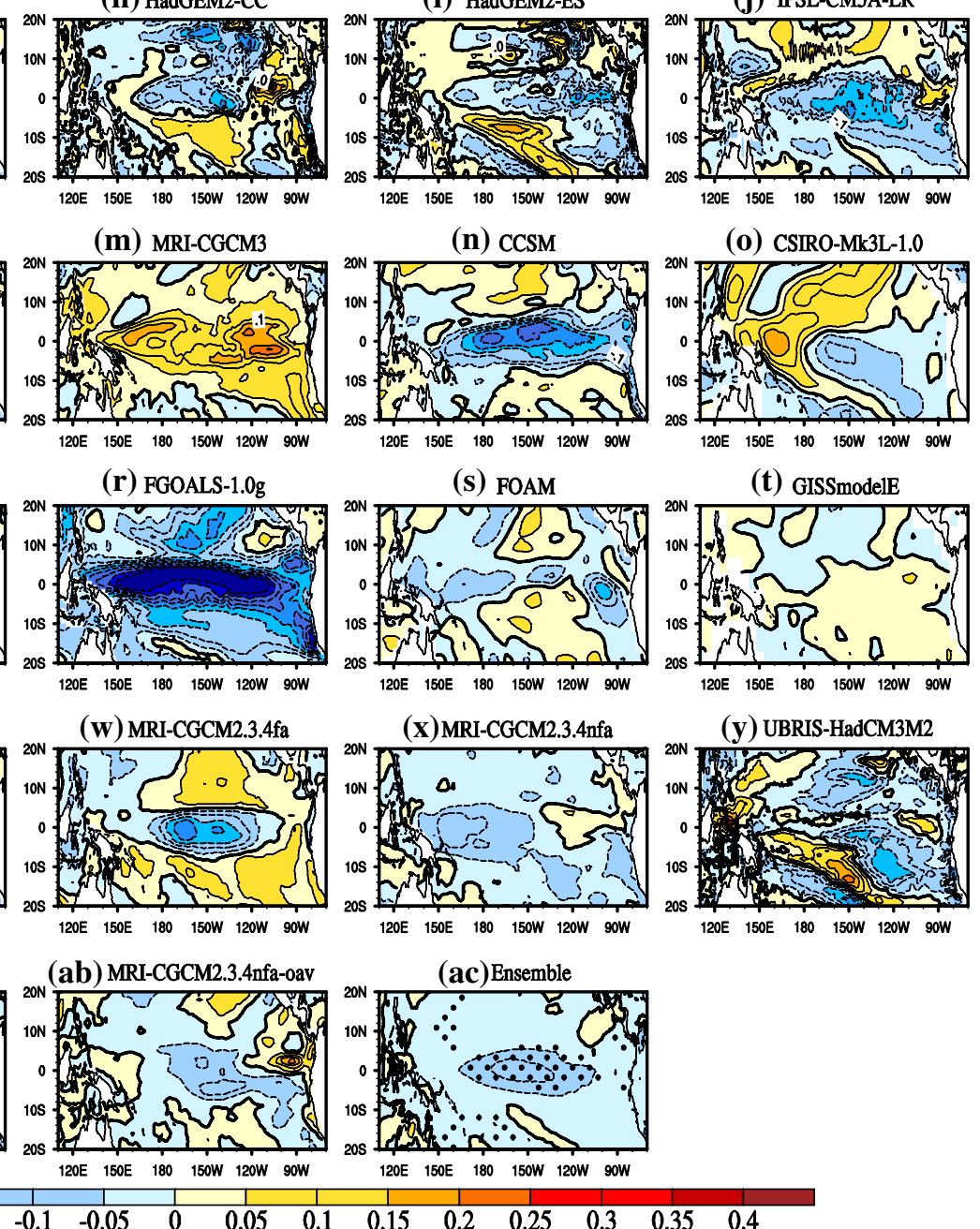

Fig. 1 The difference (MH minus PI) of the standard deviation (STD) of sea surface temperature anomaly (SSTA) from a-m 13 PMIP3 models and n-ab 15 PMIP2 models (unit: K). ac presents the multi- model ensemble result from the 28 PMIP2 and PMIP3 models. The dots indicate the area where the change in ENSO intensity goes to the same direction in more than 75 percent of the models. Unit: K models. As mentioned in Sect. 2.1, the BJ index calculation and the analyses associated with ENSO-related air-sea feedbacks below are based on 11 PMIP3 model results, due to the data availability. Figure 2 shows the relationship between the ENSO variability changes and the BJ index changes among the 11 PMIP3 models. Note that the change in the STD of SSTA averaged over Niño3 region is used to indicate the ENSO intensity change in this study. As clearly seen from Fig. 2, the ENSO intensity changes in MH are positively correlated with the $\mathrm{BJ}$ index changes (the correlation coefficient equals to 0.81 , which exceeds the significance of
95\% based on t-test). The intermodel relationship that the ENSO variability and the BJ index vary in unison indicates that the $\mathrm{BJ}$ index could serve as an effective tool to study the issues related to ENSO variability change in MH. Physically, the decrease in $\mathrm{BJ}$ index in $\mathrm{MH}$ relative to PI indicates that the ocean-atmosphere coupled system becomes more stable in $\mathrm{MH}$, and vice versa. This more stable ocean-atmosphere coupled system is unfavorable for the ENSO perturbation's growth and therefore leads to a weakening in ENSO variability in MH than that in PI. 


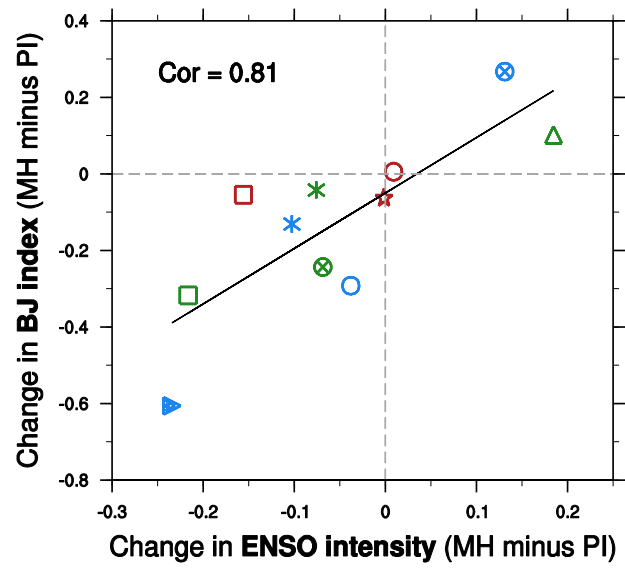

Fig. 2 The scatter diagram illustrating the relationship between the ENSO intensity change (X-axis; unit: $\mathrm{K}$ ) and the BJ index change (Y-axis; unit: year ${ }^{-1}$ ) among the 11 PMIP3 models. The correlation coefficient is 0.81 , which is above the $95 \%$ t-test significance level. Note that the models presented here are the models that have provided all the required monthly datasets for BJ-index calculation

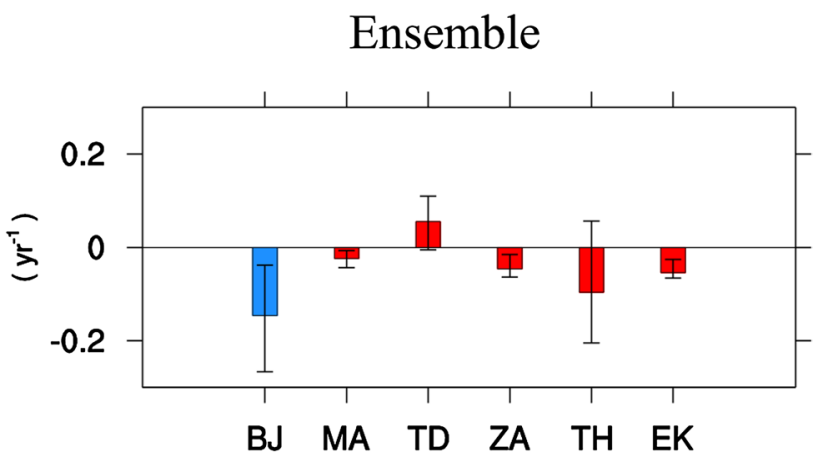

Fig. 3 The 11 PMIP3 model ensemble result of the changes in the BJ index and its five contributing terms (unit: year ${ }^{-1}$ ), including the mean advection feedback (MA term), thermodynamic damping feedback (TD term), zonal-advection feedback (ZA term), thermocline feedback (TH term), and Ekman feedback (EK term). The whiskers indicate 25 and 75 percentiles, respectively

Also, as shown in Fig. 3, the MME mean shows a decrease in the $\mathrm{BJ}$ index in $\mathrm{MH}$ compared to PI, which corresponds to the MME mean ENSO variability change (Fig. 1ac). From the perspective of MME mean, what physical processes are dominant for the decrease in $\mathrm{BJ}$ index and the resultant more stable coupled system in MH than that in PI? Among the five main contributing terms of $\mathrm{BJ}$ index (see the second column to the sixth column in Fig. 3), the decrease in BJ index in $\mathrm{MH}$ relative to PI primarily induced by the weakened TH term, followed by the weakened ZA term and EK term. Note that the change in TD term (i.e., thermodynamic damping process) makes a negative contribution to the changes in $\mathrm{BJ}$ index and ENSO variability during MH. This is because the TD term is a passive response to SST changes during the

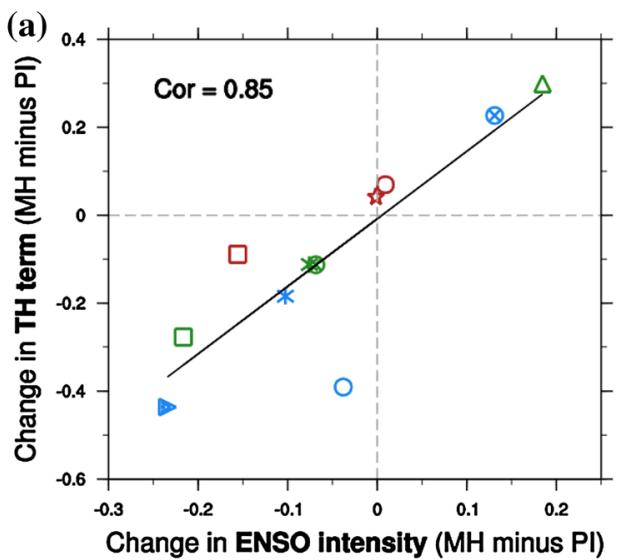

* bcc-csm1-1

O $\cos 44$

$\square$ CNRM-CM5

$\triangle$ CSIRO-Mk3-6-0

FGOALS-g2

म) HadGEM2-CC

Q HadGEM2-ES

* IPSL-CM5A-LR

O MIROC-ESM

$\square$ MPI-ESM-P

(2) MRI-CGCM3

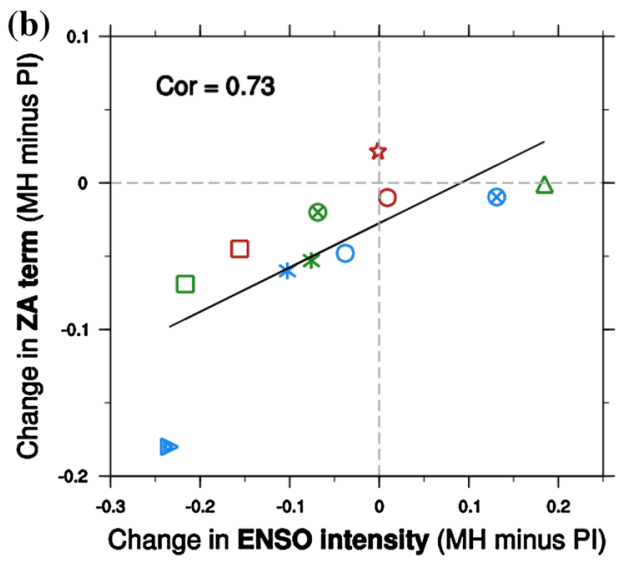

\section{* bcc-csm1-1 \\ O cosm4 \\ $\square$ CNRM-CM5 \\ $\triangle$ CSIRO-Mk3-6-0 \\ DFGOALS-g2 \\ 4) HadGEM2-CC \\ Q HadGEM2-ES \\ * IPSL-CM5A-LR \\ O MIROC-ESM \\ $\square$ MPI-ESM-P \\ (2) MRI-CGCM3}

(c)

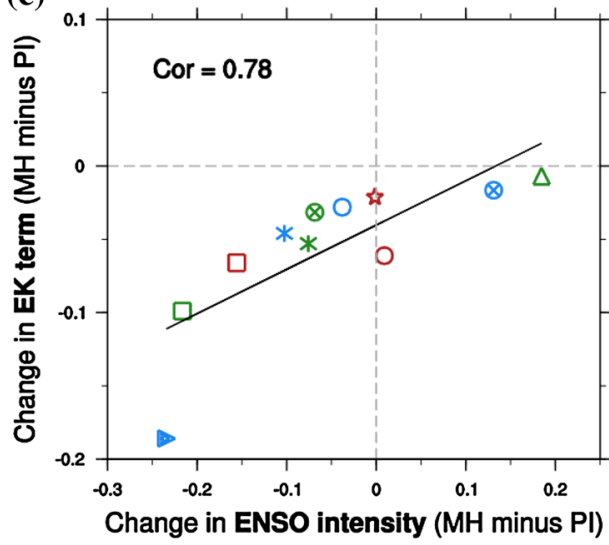

* bcc-csm1-1

O ccsm4

$\square$ CNRM-CM5

$\triangle$ CSIRO-Mk3-6-0

$\rightarrow$ FGOALS-g2

H HadGEM2-CC

Q HadGEM2-ES

* IPSL-CM5A-LR

O MIROC-ESM

$\square$ MPI-ESM-P

(2) MRI-CGCM3

Fig. 4 a Scatter diagram illustrating the relationship between the ENSO intensity change and the TH term change. b same as a but for the ZA term. c same as a but for the EK term. Here the correlation coefficients are, respective, 0.86, 0.73, and 0.78, which are above the $95 \%$ significance level

ENSO cycle, i.e., when a warm (cold) SSTA signal of ENSO starts to grow, the thermodynamic coupling at the ocean surface tends to damp it by releasing more (less) heat into the atmosphere. As such, when the ENSO intensity became weaker in MH than that in PI, the TD damping term would 
become weaker, accordingly. Therefore, the decrease of ENSO variability in MH compared to PI is attributed to the weakening in the oceanic dynamic terms (including the $\mathrm{TH}$ term, ZA term and EK term).

In addition to the MME mean results shown above, the individual model results were also investigated. As presented in Fig. 4a-c, we further plotted scatter diagrams to show the relationship between the ENSO variability change and each oceanic dynamic term change individually. It is found that the ENSO variability change is highly correlated with the change in the three terms (TH, ZA, and EK). Here the correlation coefficients between the changes in the aforementioned three terms and the ENSO amplitude change are significant at the 95\% confidence level, but the correlation coefficients between the changes in the other two terms (MA and TD) and ENSO amplitude change are insignificant (not shown). The individual model results further lend support to the above conclusion building on the MME mean results, that is, the weakening in the TH, ZA and EK terms gave rise to the decrease in BJ index and thus the suppressed ENSO variability in MH.

It is worth mentioning two points below in terms of the MME average analyses. Firstly, the BJ index and its main contribution terms were calculated for each model and each simulation, and then the MME average was obtained. As seen from the whiskers in Fig. 3, the model dispersion was considered. However, our objective is to distinguish the most dominant drivers in the framework of multi-models. Using the MME average allowed us to identify the common drivers of ENSO intensity change in MH compared to PI. Meanwhile, the individual model results presented by the scatter diagrams (Fig. 4) further revealed the relationship between the ENSO intensity change and the changes in the dominant drivers among multimodels. Secondly, such MME average approach has been employed by some recent studies for investigating the causes of ENSO intensity change in response to external forcing change (e.g., Kim et al. 2014a, b; Chen et al. 2017). For instance, Kim et al. $(2014 \mathrm{a}, \mathrm{b})$ investigated the ENSO variability change in response to future warming, via analyzing the multi-model ensemble average of the $\mathrm{BJ}$ index change and the ensemble average of the corresponding air-sea feedback changes derived from nine "better" CGCMs (despite of a certain spread of
ENSO intensity changes among the nine samples). But we applied an unweighted multiple model average here, rather than the weighted average as was done in Kim et al. (2014a, b). This is because it is difficult to distinguish the better and worse models due to that different models show different strengths and weaknesses regarding the present-day simulation, and the better/worse present-day simulation does not mean the better/ worse simulated response and changes for $\mathrm{MH}$.

It is also noted that a few studies suggested a caution for applying the diagnostic tool of $\mathrm{BJ}$ index, as some assumptions were applied in BJ index. Thus, we particularly employed an alternative diagnostic method (i.e., mixed layer heat budget, hereafter MLHB) to re-examine the key airsea feedback processes in causing ENSO intensity change in $\mathrm{MH}$ compared to PI. For detailed results, please refer to the supplementary material, which provided the specific steps of MLHB analyses and the main conclusions based on the MLHB diagnostic results. Generally speaking, the diagnostic results based on the MLHB analyses in the supplementary material are consistent with the $\mathrm{BJ}$ index diagnostic results above. This result supports that BJ index can be a useful tool for investigating ENSO intensity change in response to the external forcing change, which is also found in a relevant study by Wang et al. (2018). Additionally, through conducting the MLHB analyses step-by-step, we found that the nonlinear processes (e.g., the term 3, term 6 and term in Eq. 1 in the supplementary material) did not play a role in causing the reduced ENSO intensity change in $\mathrm{MH}$ compared to PI, as demonstrated by the individual model results (Fig. S6) and the multi-model ensemble results (Fig. S7). Based on the consistent diagnostic results derived from different diagnostic methods, we therefore will explore the physical reasons for the weakening in TH term, ZA term and EK term in MH relative to PI in the following sections.

\subsection{Cause of the change in TH term}

The TH term (i.e., $T H=\mu_{a} \times \beta_{h} \times a_{h} \times\left\langle\frac{\bar{W}}{H_{1}}\right\rangle_{E}$ ) is referred to as the thermocline feedback. The thermocline feedback is a positive feedback that tends to cause the air-sea coupled

Table 1 The 11 PMIP3 model ensemble result of the air-sea feedback sub-processes associated with the BJ index derived from the PI and MH simulations, as well as the corresponding change $(\mathrm{MH}$ minus $\mathrm{PI})$ and the change rate $($ change/PI $\times 100 \%)$

\begin{tabular}{|c|c|c|c|c|c|}
\hline & $\mu_{a}\left(\mathrm{~N} \mathrm{~m}^{-2}\right) / \mathrm{K}$ & $\beta_{h} \mathrm{~m} /\left(\mathrm{N} \mathrm{m}^{-2}\right)$ & $a_{h}\left(\mathrm{~K} \mathrm{~m}^{-1}\right)$ & $\beta_{u}\left(\mathrm{~m} \mathrm{~s}^{-1}\right) /\left(\mathrm{N} \mathrm{m}^{-2}\right)$ & $\beta_{w}\left(\mathrm{~m} \mathrm{~s}^{-1}\right) /\left(\mathrm{N} \mathrm{m}^{-2}\right)$ \\
\hline PI & $3.48 \times 10^{-3}$ & 3.68 & 30.85 & 6.10 & $-1.07 \times 10^{-4}$ \\
\hline $\mathrm{MH}$ & $3.41 \times 10^{-3}$ & 3.02 & 30.03 & 4.72 & $-0.93 \times 10^{-4}$ \\
\hline Change (MH-PI) & $-0.07 \times 10^{-3}$ & -0.66 & -0.82 & -1.38 & $0.14 \times 10^{-4}$ \\
\hline Change rate $(\%)$ & -2.0 & -18.0 & -2.7 & -22.6 & -13.1 \\
\hline
\end{tabular}

$\mu_{a}$ the response of zonal wind stress anomaly $\left(\tau_{x}^{\prime}\right)$ to SSTAs, $a_{h}$ the effect of thermocline depth change on ocean subsurface temperature anomaly, $\beta_{h}$ the response of the equatorial thermocline depth anomaly to $\tau_{x}^{\prime}, \beta_{u}$ the response of anomalous oceanic zonal current $(u)$ to $\tau_{x}^{\prime}, \beta_{w}$ the response of anomalous oceanic vertical current $\left(w^{\prime}\right)$ to $\tau_{x}^{\prime}$ 
system's instability (i.e., favoring the SST perturbation's development). The idea of this positive feedback loop is stated below. In the air-sea coupled system, assuming there is a perturbed warm SSTA signal in the eastern equatorial Pacific (EEP), it would induce an eastward zonal wind stress anomaly $\left(\tau_{x}^{\prime}\right)$; the eastward $\tau_{x}^{\prime}$ would then induce a deeperthan-normal thermocline in EEP; and the deepened thermocline would cause an anomalous warming in the ocean subsurface temperature. Through the effect of mean upwelling $(\bar{W})$ in EEP, the anomalous subsurface warming would feed back to the mixed layer temperature, which ultimately intensifies the initial warm SSTA signal. Here, the

(a) PI

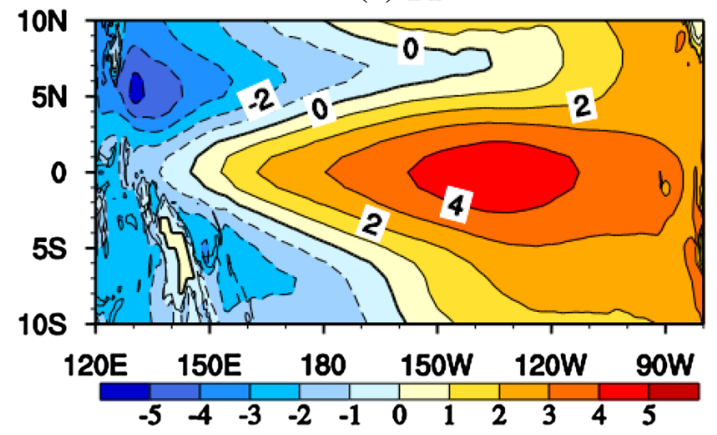

(b) MH

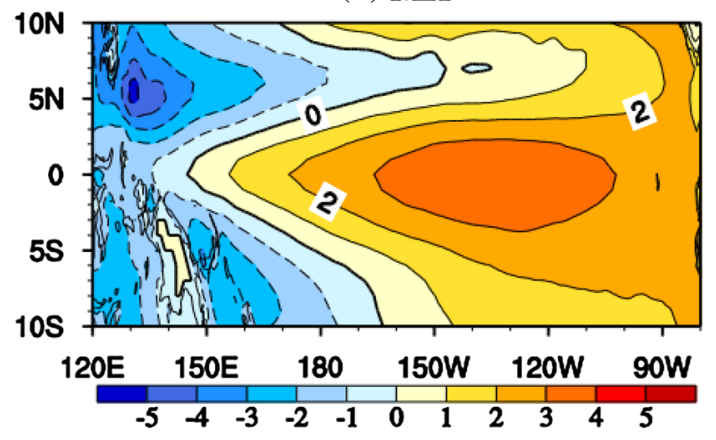

(c) Change

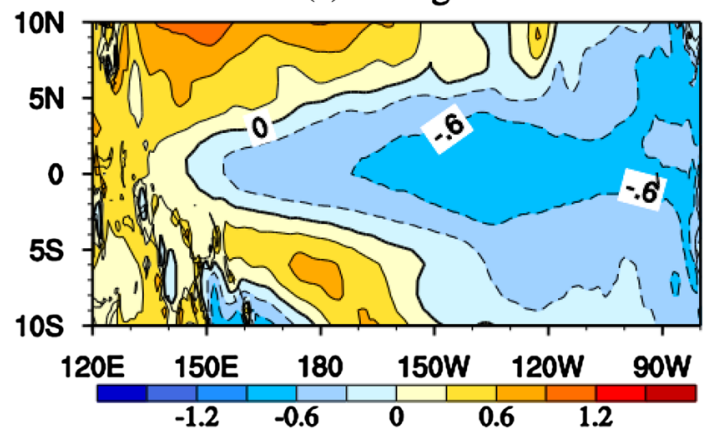

Fig. 5 The 11 PMIP3 model ensemble result of the response of the thermocline depth anomaly $\left(D^{\prime}\right)$ to zonal wind stress anomaly $\left(\tau_{x}^{\prime}\right)$ from a the PI simulation, $\mathbf{b}$ the MH simulation, and $\mathbf{c}$ the corresponding change. Here the $D^{\prime}$ response to $\tau_{x}^{\prime}$ is obtained through regressing the $S S H^{\prime}$ field onto the equatorial Pacific $\tau_{x}^{\prime}$. The unit is $\mathrm{m}\left(\mathrm{N} \mathrm{m}^{-2}\right)^{-1}$ aforementioned response of $\tau_{x}^{\prime}$ to the SSTA is represented by $\mu_{a}$, the response of thermocline depth change to $\tau_{x}^{\prime}$ is denoted by $\beta_{h}$, and the response of anomalous subsurface temperature to the thermocline depth change is denoted by $a_{h}$.

Table 1 shows the MME mean of the strength of the airsea feedbacks $\left(\mu_{a}, \beta_{h}\right.$, and $\left.a_{h}\right)$ associated with TH term in the PI and MH simulations, as well as the change and the change rate. It is noted that the strength of $\beta_{h}$ was reduced in MH compared to those in PI, while the strength of $\mu_{a}$ and $a_{h}$ marginally decreased in MH. Additionally, only a slight difference in the mean upwelling between PI and MH was found (not shown). Thus, the change in TH term is primarily determined by the change in the response of thermocline depth anomaly $\left(D^{\prime}\right)$ to $\tau_{x}^{\prime}$ (i.e., $\beta_{h}$ ).

Figure 5 shows the spatial pattern of the response of sea surface height anomaly ( $S S H^{\prime}$, a proxy of $D^{\prime}$ ) to $\tau_{x}^{\prime}$, derived from PI, MH and their difference (Fig. 5a-c). Note that a linear $D^{\prime}-S S H$ relationship has been applied here, and such a relationship was also employed in many previous studies (e.g., Kim et al. 2011a, b, 2014a, b; Chen et al. 2015; Zhu et al. 2017). In both the PI and MH simulations (Fig. 5a, b), in response to a unit eastward $\tau_{x}^{\prime}$ in equatorial Pacific, the the thermocline slope would be less, i.e., a deeper-than-normal thermocline (positive $D$, ) in EEP and a shallower-than-normal thermocline (negative $D^{\prime}$ ) in the western equatorial Pacific (hereafter WEP). Although both the PI and MH simulations replicated the general features of $\beta_{h}$, the strength of the $D^{\prime}$ response to $\tau_{x}^{\prime}$ was different between MH and PI. Specifically, a weakening in the $D^{\prime}$ response appears in MH compared to PI (Fig. 5c). The change in $D^{\prime}$ response presented in Fig. 5c agrees well with the change in the strength of $\beta_{h}$ as illustrated in Table 1.

What causes the weakening in the $S S H^{\prime}$ or $D^{\prime}$ response to $\tau_{x}^{\prime}$ in MH relative to PI? On the basis of the Sverdrup balance (Neelin 1991; Jin 1997), the relationship between $D^{\prime}$ and $\tau_{x}^{\prime}$ can be expressed as

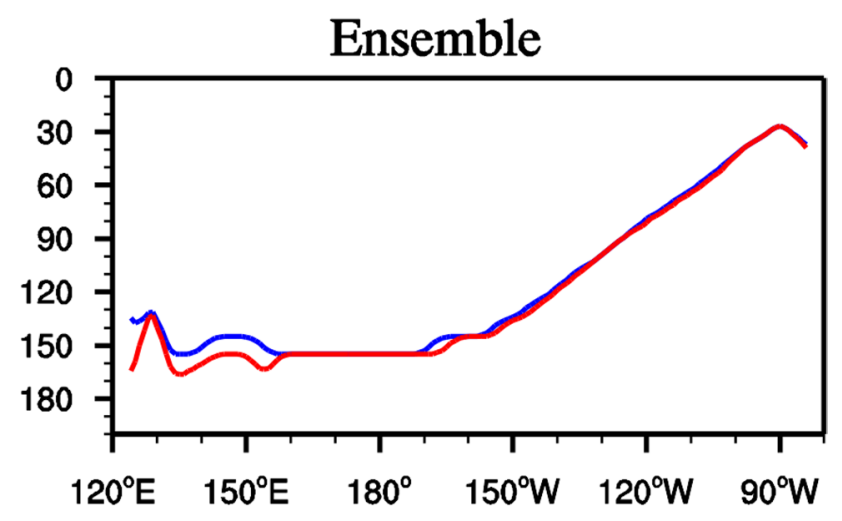

Fig. 6 The PMIP model ensemble result of the mean thermocline depth (unit: $\mathrm{m}$ ) along the equator (averaged for $5^{\circ} \mathrm{S}-5^{\circ} \mathrm{N}$ ) from the PI simulation (blue) and $\mathrm{MH}$ simulation (red). Note that the mean thermocline depth is estimated by the position where the maximum vertical gradient of mean temperature locates 
Fig. 7 The 11 PMIP3 model ensemble result of the meridional structure of normalized $\tau_{x}^{\prime}$ field [units: $\left.\mathrm{N} \mathrm{m}^{-2}\left(\mathrm{~N} \mathrm{~m}^{-2}\right)^{-1}\right]^{x}$ averaged over Niño4 longitude range $\left(160^{\circ} \mathrm{E}-150^{\circ} \mathrm{W}\right)$, derived from a the PI (blue) and $\mathrm{MH}$ (red) simulations, and $\mathbf{b}$ the corresponding change (black). Following Chen et al. (2017), the normalized $\tau_{x}^{\prime}$ field here was obtained through regressing the $\tau_{x}^{\prime}$ field onto the time series of Niño4-averaged $\tau_{x}^{\prime}$. The light blue (red) in a indicates the intermodel spread which was estimated by the intermodel standard deviation in the PI (MH) simulation

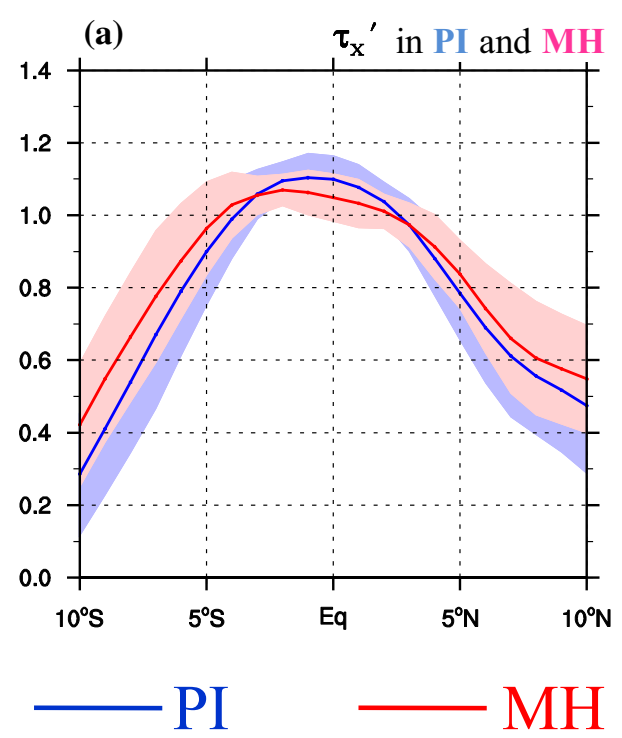

$\frac{\partial D^{\prime}}{\partial x}=\frac{\tau^{\prime}{ }_{x}}{\rho_{0} g \bar{H}}$

where $\bar{H}$ denotes the mean thermocline depth; $\rho_{0}$ and $g$ denote the seawater density and the reduced gravity, respectively. We thus firstly investigated whether the equatorial mean thermocline depth is different between PI and MH. As shown in Fig. 6, the mean thermocline depth along the equator appears nearly no change in $\mathrm{MH}$ compared to PI. Not that the unchanged mean thermocline depth from multimodel mean result is not due to the cancellation (i.e., the opposite changes), as the mean thermocline depth appears nearly no change in nearly all the models (not shown). This promotes us to focus on whether there exists a difference in the meridional structure of $\tau_{x}^{\prime}$, because recent studies (Chen et al. 2015, 2017) pointed out that if there is a change in the meridional structure of $\tau_{x}^{\prime}$ in a CGCM, there would be a change in the $D^{\prime}$ response to $\tau_{x}^{\prime}$. Figure 7 depicts the meridional structure of $\tau_{x}^{\prime}$ from the PI and MH simulations. It is noted that the meridional structure of $\tau_{x}^{\prime}$ is flatter and wider in MH compared to PI. This marked change in the meridional structure of $\tau_{x}^{\prime}$ indicates that the distribution of $\tau_{x}^{\prime}$ would be less confined at the equator in $\mathrm{MH}$, given the same boxaveraged $\tau_{x}^{\prime}$ forcing in the equatorial region. Consequently, the less confined $\tau_{x}^{\prime}$ corresponds to a weaker $\tau_{x}^{\prime}$ at the equator (Fig. 7b), which would lead to a smaller $D^{\prime}$ response in $\mathrm{MH}$ in relative to PI. Figure 8 further shows the meridional structure of SSTA derived from the two simulations. Likewise, the meridional structure of SSTA also became flatter
Fig. 8 Same as Fig. 7, but for the meridional structure of the normalized SSTA-STD field (units: $\mathrm{K} / \mathrm{K}$ ) averaged over eastern box longitude range $\left(180^{\circ} \mathrm{E}-80^{\circ} \mathrm{W}\right)$. Following Chen et al. (2017), here the SSTASTD field was normalized by the value of SSTA-STD averaged over eastern Pacific region $\left(180^{\circ} \mathrm{E}-80^{\circ} \mathrm{W}, 10^{\circ} \mathrm{S}-10^{\circ} \mathrm{N}\right)$

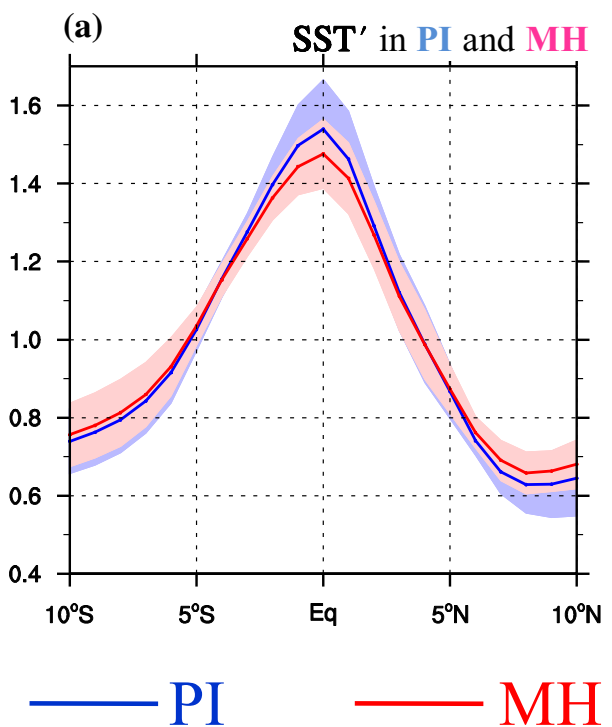


(a) PI

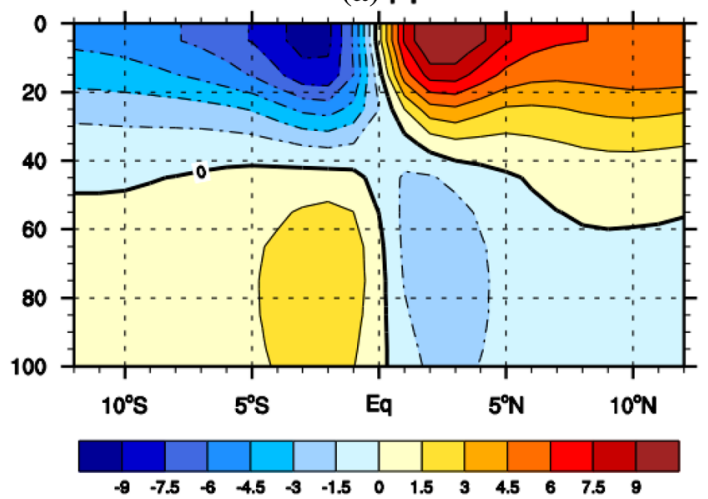

(b) $\mathrm{MH}$

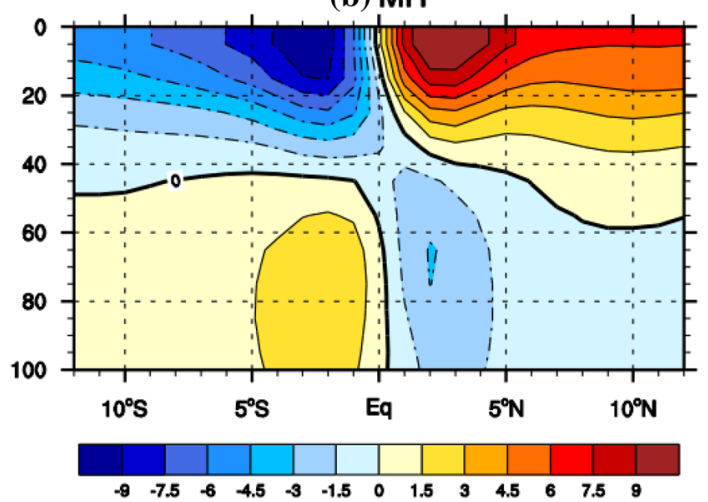

(c) Change

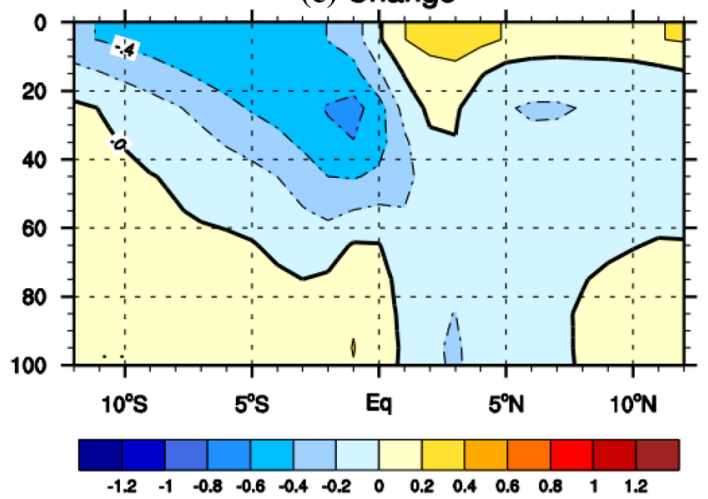

Fig. 9 The 28 PMIP model ensemble result of the mean meridional current averaged over the central-eastern Pacific $\left(160^{\circ} \mathrm{E}-90^{\circ} \mathrm{W}\right)$, derived from the a PI simulation, $\mathbf{b} \mathrm{MH}$ simulation, and $\mathbf{c}$ the corresponding change

and wider in $\mathrm{MH}$ than that in PI, in a similar manner to the change in the meridional structure of $\tau_{x}^{\prime}$. Physically, since ENSO is a coupled ocean-atmosphere system, the ENSOrelated fields (SSTA and $\tau_{x}^{\prime}$ ) naturally experienced a consistent change in the meridional structure.

Why does the ENSO meridional structure become flat in $\mathrm{MH}$ relative to that in PI? As reported by some recent studies, the ENSO meridional structure is primarily controlled by the surface poleward mean meridional current
(Zhang et al. 2009, 2013; Zhang and Jin 2012; Chen et al. 2015). Figure 9 shows the mean meridional currents from the PI simulation (Fig. 9a), the MH simulation (Fig. 9b), and the corresponding change (Fig. 9c). As shown in Fig. 9a, b, the mean meridional currents exhibit the shallow meridional overturning circulation over the Pacific region in the PI and $\mathrm{MH}$ simulations, characterized by a poleward flow in surface layer and an equatorward flow beneath the surface layer. As shown in Fig. 9c, the surface poleward mean meridional current become strengthened in MH compared to that in PI. Consequently, the strengthened surface poleward flow results in a wider and flatter meridional structure of ENSO-related SSTA and $\tau_{x}^{\prime}$ in MH than that in PI.

\subsection{Cause of the change in ZA term}

The ZA term $\left(Z A=\mu_{a} \times \beta_{u} \times\left\langle-\frac{\partial \bar{T}}{\partial x}\right\rangle_{E}\right)$ is referred to as the zonal advection feedback. It consists of the zonal gradient of mean temperature $\left(\frac{\partial T}{\partial x}\right)$ and two air-sea feedback sub-processes (say, $\mu_{a}$ and $\beta_{u}$ ). As described above, $\beta_{u}$ represents the response of anomalous oceanic zonal current (hereafter $u^{\prime}$ ) to $\tau_{x}^{\prime}$. As shown in Table 1, the strength of $\beta_{u}$ was reduced in MH compared to those in PI, while the strength of $\mu_{a}$ marginally decreased in MH. Additionally, there is only a slight difference in the $\frac{\partial \bar{T}}{\partial x}$ between PI and MH (not shown). Thus, the weakened ZA term in MH compared to PI is primarily attributed to the reduction in the air-sea feedback of $\beta_{u}$.

Figure 10 shows the vertical-zonal section of the response of $u^{\prime}$ to $\tau_{x}^{\prime}$ (see the shaded in Fig. 10a-c) across the equatorial Pacific, derived from the two simulations and their difference. As clearly shown in Fig. 10a, b, in both the PI and MH simulations, an eastward $u^{\prime}$ would occur over the equatorial Pacific as a result of a unit eastward $\tau_{x}^{\prime}$ at the equator. However, it is found that the strength of the $u^{\prime}$ response to $\tau_{x}^{\prime}$ was weaker in MH than that in PI (see the shaded in Fig. 10c), which represents the aforementioned decrease of the $\beta_{u}$ in $\mathrm{MH}$ relative to PI.

It is suggested by the previous studies (e.g., Su et al. 2010; Chen et al. 2015, 2016) that the $u^{\prime}$ along the equator consists of two main components, including the anomalous geostrophic current $\left(u_{g}^{\prime}\right)$ and the anomalous Ekman current $\left(u_{e}^{\prime}\right)$. To account for the change of the $\beta_{u}$ in MH compared to PI, we further diagnosed the two components of $u^{\prime}$ based upon the following equations (Su et al. 2010, 2014).

$u_{g}^{\prime}=-\frac{g \partial^{2} D^{\prime}}{\beta \partial y^{2}}$

$u_{e}^{\prime}=\frac{1}{\rho H_{1}} \frac{r_{s} \tau^{\prime}{ }_{x}+\beta y \tau_{y}^{\prime}}{r_{s}^{2}+(\beta y)^{2}}$ 
(a) PI

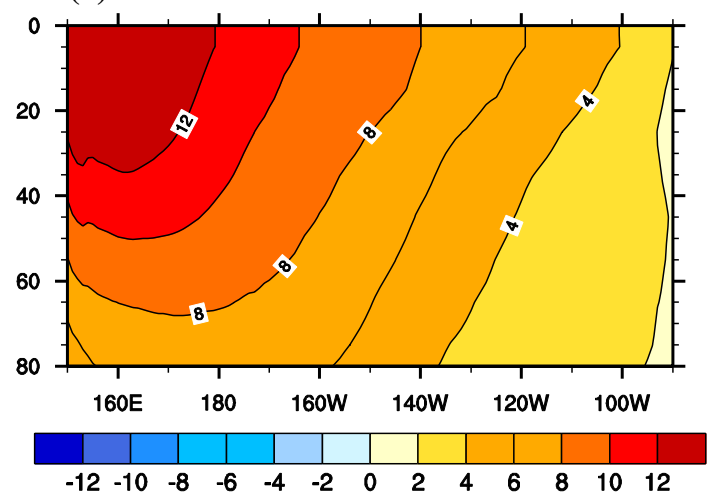

(b) $\mathrm{MH}$

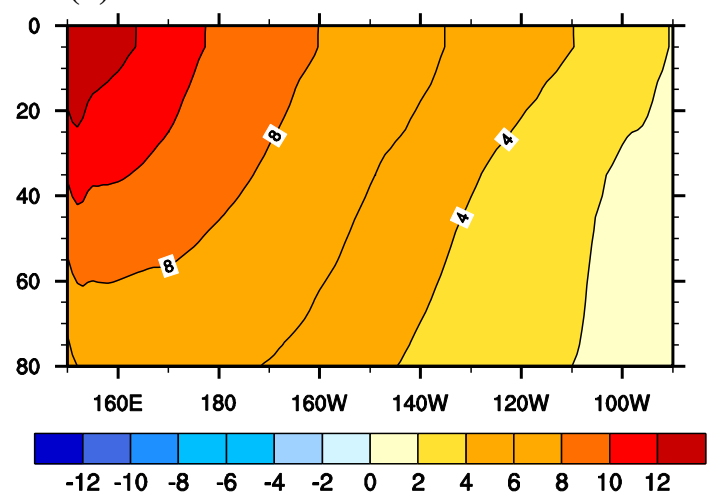

(c) $\mathrm{MH}$ minus $\mathrm{PI}$

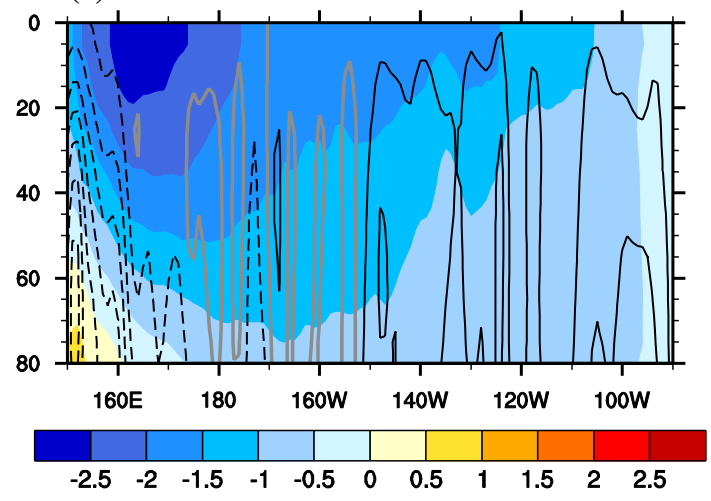

Fig. 10 Vertical-zonal section along the equator (averaged between $5^{\circ} \mathrm{S}$ and $\left.5^{\circ} \mathrm{N}\right)$ of the $u^{\prime}$ response to the equatorial Pacific $\tau_{x}^{\prime}$ [shading; units: $\left.\left(\mathrm{m} \mathrm{s}^{-1}\right) /\left(\mathrm{N} \mathrm{m}^{-2}\right)\right]$ derived from the 11 PMIP3 model ensemble result. Specifically, a is for the PI simulation, $\mathbf{b}$ for the MH simulation and $\mathbf{c}$ for the corresponding change. The contours in $\mathbf{c}$ denote the difference in the $w^{\prime}$ response to the equatorial Pacific $\tau_{x}^{\prime}$ [contour interval is $1.0 \times 10^{-5}\left(\mathrm{~m} \mathrm{~s}^{-1}\right) /\left(\mathrm{N} \mathrm{m}^{-2}\right)$; black solid curves denote positive value, black dashed curves denote negative value, and gray curve is the zero line]

where $\beta$ is the planetary vorticity gradien, $\tau_{y}^{\prime}$ is the meridional wind stress anomaly, and $r_{s}$ is a constant Rayleigh damping coefficient. As clearly shown in Table 2, in both the PI and MH simulations, the response of $u^{\prime}$ to $\tau_{x}^{\prime}$ is dominated by the response of $u_{g}{ }^{\prime}$ to $\tau_{x}^{\prime}$, whereas the contribution of the
Table 2 The 11 PMIP3 model ensemble result of the responses of zonal current anomaly $\left(u^{\prime}\right)$ averaged over $0-50 \mathrm{~m}$, zonal geostrophic current anomaly $\left(u_{\mathrm{g}}{ }^{\prime}\right)$ and zonal Ekman current anomaly $\left(u_{e}{ }^{\prime}\right)$ along the eastern equatorial Pacific $\left(180^{\circ} \mathrm{W}-80^{\circ} \mathrm{W}, 5^{\circ} \mathrm{S}-5^{\circ} \mathrm{N}\right)$ to equatorial $\tau_{x}^{\prime}$, derived from the PI simulation, $\mathrm{MH}$ simulation, and the corresponding change

\begin{tabular}{llll}
\hline & PI & MH & Change (MH-PI) \\
\hline$u^{\prime}$ & 6.10 & 4.72 & -1.38 \\
$u_{\mathrm{g}}{ }^{\prime}$ & 5.23 & 4.07 & -1.16 \\
$u_{e}{ }^{\prime}$ & 1.02 & 0.96 & -0.06 \\
\hline
\end{tabular}

Here the unit is $\mathrm{m} \mathrm{s}^{-1}\left(\mathrm{~N} \mathrm{~m}^{-2}\right)^{-1}$

response of $u_{e}^{\prime}$ to $\tau_{x}^{\prime}$ is minor. Regarding the $u_{g}{ }^{\prime}$ response to $\tau_{x}^{\prime}$, previous studies (e.g., Su et al. 2014; Chen et al. 2015, 2016) reported that the change in the $u_{g}{ }^{\prime}$ response is closely linked to the change in the $D^{\prime}$ response to $\tau_{x}^{\prime}$. This is because the maximum $D^{\prime}$ over the EEP is centered at the equator (Fig. 5a, b), the weakened $D^{\prime}$ response corresponds to a smaller value of $-\frac{\partial^{2} D^{\prime}}{\partial y^{2}}$ and hence weakened $u_{g}{ }^{\prime}$ response (refer to Eq. 11). Therefore, the difference of $\beta_{u}$ between PI and $\mathrm{MH}$ is also linked to the aforementioned difference in the $D^{\prime}$ response to $\tau_{x}^{\prime}$.

\subsection{Cause of the change in EK term}

The EK term $\left(E K=\mu_{a} \times \beta_{w} \times\left\langle-\frac{\partial \bar{T}}{\partial z}\right\rangle_{E}\right)$ is referred to as Ekman feedback. It consists of the vertical gradient of mean temperature $\left(\frac{\partial \bar{T}}{\partial z}\right)$ and two air-sea feedback sub-processes (say, $\mu_{a}$ and $\beta_{w}$ ). As described above, $\beta_{w}$ represents the response of anomalous upwelling (hereafter $w^{\prime}$ ) to $\tau_{x}^{\prime}$. As shown in Table 1, the strength of $\beta_{w}$ was reduced in $\mathrm{MH}$ compared to those in PI, whereas the strength of $\mu_{a}$ marginally decreased in $\mathrm{MH}$. Additionally, there is only a slight difference in the $\frac{\partial \bar{T}}{\partial z}$ between PI and MH (not shown). Thus, the weakened EK term in MH compared to PI is induced by the reduced strength in the air-sea feedback of $\beta_{w}$.

Why does the strength of $\beta_{w}$ become weaker in $\mathrm{MH}$ than PI? It may be related to the weakened response of $u^{\prime}$ to $\tau_{x}^{\prime}$ (i.e., the weakened $\beta_{u}$ ) in $\mathrm{MH}$ compared to that in PI, because it has been demonstrated that the change in the $w^{\prime}$ response to $\tau_{x}^{\prime}$ in the equatorial region is generally coherent with the change in the $u^{\prime}$ response to $\tau_{x}^{\prime}$ due to the mass conservation (e.g., Wang et al. 2018). Specifically, in response to a unit eastward $\tau_{x}^{\prime}$, the weakened response of $u^{\prime}$ in $\mathrm{MH}$ relative to that in PI would weaken the surface water convergence, and hence causes a weakening in the anomalous downwelling ( $w^{\prime}$ $<0$ ) in the EEP (see the contours in Fig. 10c). As a result, the weaker $\beta_{w}$ ultimately results in the reduction in EK term in $\mathrm{MH}$ than that in PI. 


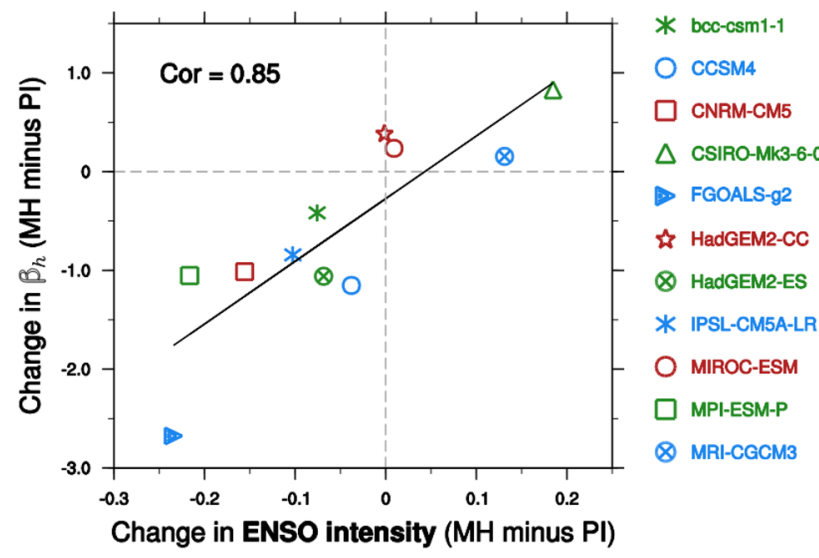

Fig. 11 Scatter diagram illustrating the relationship between the ENSO intensity change (X-axis; unit: $\mathrm{K}$ ) and the change in $\beta_{h}$ [Y-axis; unit: $\mathrm{m}\left(\mathrm{N} \mathrm{m}^{-2}\right)^{-1}$ ] among the 11 PMIP3 models. The correlation coefficient is 0.85 , which is above the $95 \% \mathrm{t}$-test significance level

Our quantitative analyses above elucidated that the change in the $D^{\prime}$ response to $\tau_{x}^{\prime}$ (i.e., $\beta_{h}$ ) could lead to the change in the TH, ZA, and EK terms and thus alter the ENSO variability in MH. To test this hypothesis, we further plotted a scatter diagram to illustrate the relationship between the change in $\beta_{h}$ and the change in ENSO variability. As shown in Fig. 11, it is noted that the change in $\beta_{h}$ is positively correlated with the ENSO variability change (here the correlation coefficient exceeds the 95\% significance level). This result further confirms our argument, that is, the change in $\beta_{h}$ holds a key for the weakening in the oceanic dynamic terms and the resultant reduction in ENSO intensity in $\mathrm{MH}$.

\section{Summary}

In the present modeling study, we investigated the physical cause of the ENSO intensity change in MH climate compared to present-day climate, through analyzing a suite of simulations from PMIP2 and PMIP3 models. The majority of PMIP2 and PMIP3 models show a decrease in ENSO intensity in $\mathrm{MH}$ compared to PI, although the degree of the decrease varies across the models. To identify the dominant factors that lead to the reduced ENSO activity in $\mathrm{MH}$, we employed the $\mathrm{BJ}$ index to quantify the strength of the dynamic and thermodynamic air-sea feedback processes associated with the ENSO variability. The quantitative diagnostic results show that the suppressed ENSO variability in $\mathrm{MH}$ is primarily caused by the weakened $\mathrm{TH}$ term, followed by the weakened ZA and EK terms. In contrast, the change in the thermodynamic term makes a negative contribution to the suppressed ENSO variability. Our analyses further demonstrate that the weakening in the air-sea feedback of $\beta_{h}$ (i.e., the $D^{\prime}$ response to $\tau_{x}^{\prime}$ ) plays a decisive role for the reduction in the TH, ZA and EK terms in $\mathrm{MH}$, and the reduced $\beta_{h}$ is further linked to the enhanced surface poleward mean meridional current.

As shown in the schematic diagram (Fig. 12), the possible explanation for the suppressed ENSO variability in $\mathrm{MH}$ was summarized. Among many aspects of the mean
Fig. 12 A schematic diagram that summarized the possible explanation for the reduced ENSO intensity in MH proposed in this study

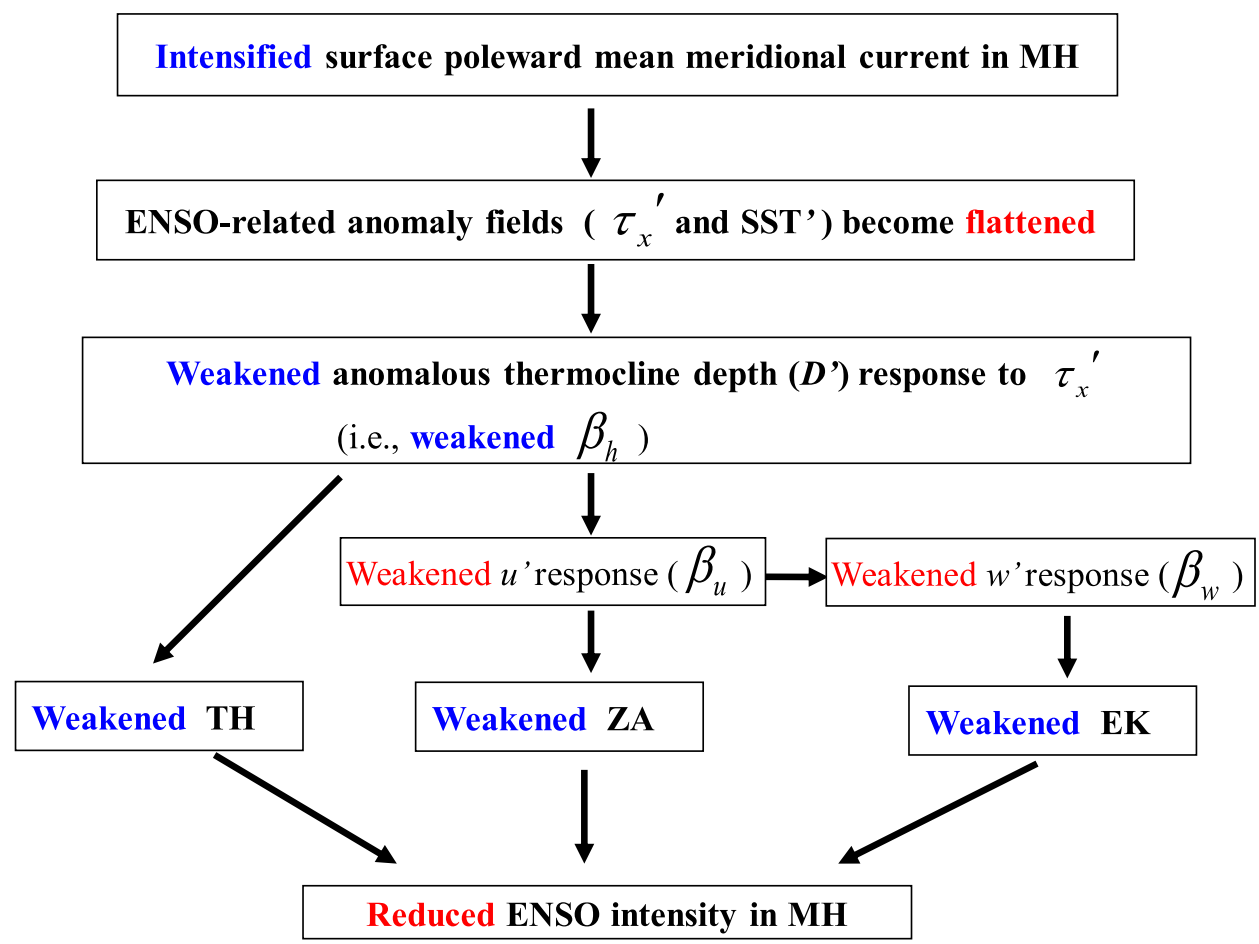


state changes under the $\mathrm{MH}$ orbital forcing, the enhanced surface poleward mean meridional current was identified as a dominant factor in driving the ENSO variability change in $\mathrm{MH}$. The enhanced mean surface poleward meridional current gave rise to a wider and flatter meridional structure of ENSO-related anomaly fields (i.e., the SSTA and $\tau_{x}^{\prime}$ ), which leads to the $\tau_{x}^{\prime}$ at the equator becomes weaker in MH than that in PI. As a result, this weaker $\tau_{x}^{\prime}$ at the equator induced the response of $D^{\prime}$ less effectively (i.e., the strength of $\beta_{h}$ was weakened in MH relative to PI). Such weakened $\beta_{h}$ directly contributes to the reduction in the TH term. On the other hand, the weakened $\beta_{h}$ or the weakened $D^{\prime}$ response could cause a weakening in the $u_{g}{ }^{\prime}$ response to $\tau_{x}^{\prime}$, which induces the weakening in the $u^{\prime}$ response to $\tau_{x}^{\prime}$ (i.e., $\beta_{u}$ ) and the resulting weakened ZA term in MH. Meanwhile, due to the mass conservation, the weakened $u^{\prime}$ response to $\tau_{x}^{\prime}$ corresponds to a weakening in the $w^{\prime}$ response to $\tau_{x}^{\prime}$ (i.e, $\beta_{w}$ ). Consequently, the weakened $\beta_{w}$ leads to the weakened EK term in MH. Eventually, the weakening in the TH, ZA and EK terms collectively suppressed the ENSO variability in MH compared to PI.

\section{Discussions}

In the current study, we unveiled that the change in the wind-thermocline feedback (i.e., $\beta_{h}$ ) is a key factor that regulate the ENSO variability in MH through its impact on ocean dynamics. It is worth noting that a recent study that focused on the response of ENSO variance to global warming also suggested that $\beta_{h}$ is the key factor that determines the ENSO variance change (Kim et al. 2014a, b; Chen et al. 2015, 2017). This indicates that among a number of ENSO-related air-sea feedbacks, the air-sea feedback of $\beta_{h}$ seems to be more susceptible to external forcing change, and that we may need to pay more attention to the $\beta_{h}$ when studying the issues associated with the ENSO variability change. The main difference between Kim et al. (2014a, b) and our current study is discussed below. Their study attributed the change in $\beta_{h}$ to the change in the mean zonal thermocline depth based upon the future projection simulations from nine CMIP5 models; while we found that there is nearly no change in the mean zonal thermocline depth in the MH simulation compared to PI simulation (Fig. 6), and we suggested that the $\beta_{h}$ change is due to the change in the meridional structure of $\tau_{x}^{\prime}$, which is further linked to the change in the surface mean meridional current.

It is noteworthy that understanding the linkage between the mean state change (e.g., the mean meridional current change) and $\mathrm{MH}$ orbital forcing is another complex issue. A recent study (Tian et al. 2018) found that the tropical Pacific Walker circulation is strengthened in
MH compared to PI in the PMIP2 and PMIP3 simulations. They suggested that in response to the $\mathrm{MH}$ orbital forcing, the Asian and North African monsoon precipitation was strengthened due to large-scale surface warming in Northern Hemisphere in boreal warm seasons, which caused the intensified large-scale thermally east-west circulation and the corresponding increase in the surface trade wind over the tropical equatorial Pacific. Meanwhile, some relevant studies (Chen et al. 2015, 2017) have shown that the change in the surface poleward mean meridional current is mainly caused by the change in the mean surface zonal wind due to the Ekman transport effect, through conducting sensitivity experiments with an ocean general circulation model. Therefore, the enhanced surface mean meridional currents under $\mathrm{MH}$ orbital forcing revealed in this study is probably associated with the strengthened Pacific trade wind in MH.

Several recent modeling studies have also carried out analyses regarding the ENSO variability change in $\mathrm{MH}$ relative to that in PI. The following discussion is about the consistence and difference between the others' modeling studies and the current study. Using two coupled models from NCAR Climate System Model (CSM3) and Hadley Center Model (HadCM3) that participated in PMIP2, Roberts et al. (2014) pointed out that the reduced ENSO variance was, respectively, attributed to the reduction in the SST-wind feedback (which is analogous to the $\mu_{a}$ as introduced in this study) in CSM3 and the reduction in the oceanic temperature-wind feedback (which is analogous to the integrated effect of $\beta_{h} \cdot a_{h}$ ) in HadCM3. Our results also found that all the aforementioned air-sea feedbacks- $\mu_{a}$, $\beta_{h}$ and $a_{h}$ were weakened in $\mathrm{MH}$ relative to PI, which is consistent with Roberts et al. (2014). But our quantitative analyses further demonstrated that the weakened $\beta_{h}$ is the key factor for the lower ENSO activity in $\mathrm{MH}$, while the reductions in $\mu_{a}$ and $a_{h}$ are minor, based on the simulations by a range of PMIP3 models. Two recent studies (Tian et al. 2017; Chen et al. 2018) also suggested that the mean STC change is important for the ENSO variability change in $\mathrm{MH}$, which is supported by the current finding based on multi-model simulation results. One major difference between their study and ours is that Tian et al. (2017) only investigated two model simulations (one simulation even adopted the flux adjustment scheme) in details and they only conducted the MLHB analysis, and Chen et al. (2018) only employed a single coupled model even though it exhibits excellent performance in simulating the present-day ENSO behaviors; while our conclusions were mainly based on the 13 PMIP3 models and we conducted two different diagnostic methods (BJ index and MLHB), which allowed us to identify the common drivers of ENSO intensity change in MH. Another recent study (An and Bong 2017) suggested that the reduced ENSO variability 
was caused by the strengthened dynamic damping (i.e., the MA term), which is due to the enhanced mean meridional currents. Our results also showed that the mean meridional currents and the corresponding MA term were intensified in MH compared to PI (i.e., the negative value of MA term becomes more negative in $\mathrm{MH}$ ), which is consistent with their finding. However, we found that the role of the MA term change in altering the ENSO variability was relatively smaller than the other three ocean dynamic terms. The discrepancy between their finding and ours might arise from that only the selected growth season (i.e., JuneDecember) was used in their calculation of the BJ index, while the entire 12 calendar months were used in our calculation. It is suggested that the choice of calculating BJ index through using the entire 12 calendar months (i.e., using all the monthly outputs) may be better, because the growth season of ENSO in the PMIP models is not always June-December (figure not shown), especially for the MH; and using all the monthly outputs to calculate the BJ index has been widely used in many relevant studies (e.g., Kim et al. 2011a, b, 2014a, b; Liu et al. 2014; Lübbecke and McPhaden 2014; Lu et al. 2016; Zhu et al. 2017), as the BJ index was created to measure the overall stability of ocean-atmosphere coupled system associated with ENSO.

It is worth mentioning that this study benefits from that the PMIP3 model simulation provided the monthly resolved datasets (including the ENSO-related three-dimensional oceanic variables, such as $u, v, w$, and $T$ ), which allowed us to conduct the quantitative analyses on a series of air-sea feedbacks associated with ENSO variability. But the possible explanation for the suppressed ENSO activity in MH proposed in this study was built on the model world, which is needed to be further tested with the aid of high time-space resolution paleoclimate proxy datasets in future.

Acknowledgements We would like to thank three anonymous reviewers for insightful suggestions and comments. This work was jointly supported by the National Key Research and Development Program on Monitoring, Early Warning and Prevention of Major Natural Disaster (2018YFC1506002), the National Natural Science Foundation of China (No. 41376002, No. 41705059, No. 41630423, and No. 41606011), the Startup Foundation for Introducing Talent of NUIST, the LASG Open Project, the open fund of State Key Laboratory of Loess and Quartary Geology (SKLLQG1802), and National 973 project 2015CB453200. This work is also a contribution to the JPI Belmont project PACMEDY (ANR-15-JCLI-0003-01). We acknowledge the World Climate Research Program's Working Group on Coupled Modelling, which is responsible for CMIP, and we thank the PMIP3 modeling groups for producing and making available their model output. The U.S.Department of Energy's Program for Climate Model Diagnosis and Intercomparison provides coordinating support for CMIP, and led development of software infrastructure in partnership with the Global Organization for Earth System Science Portals, the ESGF distributed database. PMIP3 simulations are available through PMIP website https ://pmip3.1sce.ipsl.fr/. This is IPRC contribution number 1361, ESMC number 248.
OpenAccess This article is distributed under the terms of the Creative Commons Attribution 4.0 International License (http://creativeco mmons.org/licenses/by/4.0/), which permits unrestricted use, distribution, and reproduction in any medium, provided you give appropriate credit to the original author(s) and the source, provide a link to the Creative Commons license, and indicate if changes were made.

\section{References}

An S-I, Bong H (2017) Feedback process responsible for the suppression of ENSO activity during the mid-Holocene. Theor Appl Climatol. https://doi.org/10.1007/s00704-017-2117-6

An S-I, Choi J (2014) Mid-Holocene tropical Pacific climate state, annual cycle, and ENSO in PMIP2 and PMIP3. Clim Dyn 43:957970. https://doi.org/10.1007/s00382-013-1880-z

Bellenger H, Guilyardi É, Leloup J, Lengaigne M, Vialard J (2014) ENSO representation in climate models: from CMIP3 to CMIP5. Clim Dyn 42:1999-2018

Braconnot P et al (2007a) Results of PMIP2 coupled simulations of the Mid-Holocene and Last Glacial maximum-Part 1: experiments and large-scale features. Clim Past 3:261-277. https://doi. org/10.5194/cp-3-261-2007

Braconnot $\mathrm{P}$ et al (2007b) Results of PMIP2 coupled simulations of the Mid-Holocene and Last Glacial Maximum-Part 2: feedbacks with emphasis on the location of the ITCZ and mid- and high latitudes heat budget. Clim Past 3:279-296. https://doi.org/10.5194/ cp-3-279-2007

Braconnot $\mathrm{P}$ et al (2012a) Evaluation of climate models using palaeoclimatic data. Nat Clim Change 2:417. https://doi.org/10.1038/ nclimate 1456

Braconnot P, Luan Y, Brewer S, Zheng W (2012b) Impact of Earth's orbit and freshwater fluxes on Holocene climate mean seasonal cycle and ENSO characteristics. Clim Dyn 38:1081-1092. https ://doi.org/10.1007/s00382-011-1029-x

Brown J, Collins M, Tudhope AW, Toniazzo T (2008) Modelling midHolocene tropical climate and ENSO variability: towards constraining predictions of future change with palaeo-data. Clim Dyn 30:19-36. https://doi.org/10.1007/s00382-007-0270-9

Bush ABG (1999) Assessing the impact of mid-Holocene insolation on the atmosphere-ocean system. Geophys Res Lett 26:99-102. https://doi.org/10.1029/1998g1900261

Chen L, Li T, Yu Y (2015) Causes of strengthening and weakening of ENSO amplitude under global warming in four CMIP5 models. J Clim 28:3250-3274. https://doi.org/10.1175/jcli-d-14-00439.1

Chen L, Yu Y, Zheng W (2016a) Improved ENSO simulation from climate system model FGOALS-g1.0 to FGOALS-g2. Clim Dyn 47:2617-2634. https://doi.org/10.1007/s00382-016-2988-8

Chen L, Li T, Behera SK, Doi T (2016b) Distinctive precursory airsea signals between regular and super El Niños. Adv Atmos Sci 33:996-1004. https://doi.org/10.1007/s00376-016-5250-8

Chen L, Li T, Yu Y, Behera SK (2017) A possible explanation for the divergent projection of ENSO amplitude change under global warming. Clim Dyn 49:3799-3811. https://doi.org/10.1007/ s00382-017-3544-x

Chen L, Wang L, Li T, Liu J (2018) Drivers of reduced ENSO variability in mid-Holocene in a coupled model. Clim Dyn. https:// doi.org/10.1007/s00382-018-4496-5

Chiang JCH, Fang Y, Chang P (2009) Pacific climate change and ENSO activity in the mid-Holocene. J Clim 22:923-939. https ://doi.org/10.1175/2008jcli2644.1

Clement AC, Seager R, Cane MA (1999) Orbital controls on the El Niño/Southern Oscillation and the tropical climate. Paleoceanography 14:441-456. https://doi.org/10.1029/1999pa900013 
Clement AC, Seager R, Cane MA (2000) Suppression of El Niño during the Mid-Holocene by changes in the Earth's orbit. Paleoceanography 15:731-737

Cobb KM, Charles CD, Cheng H, Edwards RL (2003) El Niño/ Southern Oscillation and tropical Pacific climate during the last millennium. Nature 424:271. https://doi.org/10.1038/natur e01779

Cobb KM et al (2013) Highly variable El Niño-Southern oscillation throughout the Holocene. Science 339:67-70. https://doi. org/10.1126/science. 1228246

Collins M et al (2010) The impact of global warming on the tropical Pacific Ocean and El Niño. Nat Geosci 3:391-397

Emile-Geay J et al (2016) Links between tropical Pacific seasonal, interannual and orbital variability during the Holocene. Nat Geosci 9:168-173. https://doi.org/10.1038/ngeo2608

Feng J, Li J-P (2011) Influence of El Niño Modoki on spring rainfall over south China. J Geophys Res Atmos 116:D13102. https://doi. org/10.1029/2010jd015160

Feng J, Li J-P (2013) Contrasting impacts of two types of ENSO on the Boreal Spring Hadley circulation. J Clim 26:4773-4789. https:// doi.org/10.1175/JCLI-D-12-00298.1

Harrison SP et al (2015) Evaluation of CMIP5 palaeo-simulations to improve climate projections. Nat Clim Change 5:735. https://doi. org/10.1038/nclimate2649

Hua L, Chen L, Rong X, Su J, Wang L, Li T, Yu Y (2018) Impact of atmospheric model resolution on simulation of ENSO feedback processes: a coupled model study. Clim Dyn 51:3077-3092. https ://doi.org/10.1007/s00382-017-4066-2

Jin F-F (1997) An equatorial ocean recharge paradigm for ENSO. Part I: conceptual model. J Atmos Sci 54:811-829

Jin F-F, Kim ST, Bejarano L (2006) A coupled-stability index for ENSO. Geophys Res Lett 33:L23708

Karamperidou C, Di Nezio PN, Timmermann A, Jin F-F, Cobb KM (2015) The response of ENSO flavors to mid-Holocene climate: proxy interpretation. Paleoceanography 30:2014PA002742. https ://doi.org/10.1002/2014pa002742

Kim ST, Jin F-F (2011a) An ENSO stability analysis. Part II: results from the twentieth and twenty-first century simulations of the CMIP3 models. Clim Dyn 36:1609-1627

Kim ST, Jin F-F (2011b) An ENSO stability analysis. Part I: results from a hybrid coupled model. Clim Dyn 36:1593-1607

Kim ST, Cai W, Jin F-F, Yu J-Y (2014a) ENSO stability in coupled climate models and its association with mean state. Clim Dyn 42:3313-3321

Kim ST, Cai W, Jin F-F, Santoso A, Wu L, Guilyardi E, An S-I (2014b) Response of El Niño sea surface temperature variability to greenhouse warming. Nat Clim Change 4:786-790. https://doi. org/10.1038/nclimate2326

Kitoh A, Murakami S (2002) Tropical Pacific climate at the midHolocene and the last glacial maximum simulated by a coupled ocean-atmosphere general circulation model. Paleoceanography 17:1047. https://doi.org/10.1029/2001pa000724

Koutavas A, Joanides S (2012) El Niño-Southern Oscillation extrema in the Holocene and last glacial maximum. Paleoceanography 27:PA4208. https://doi.org/10.1029/2012pa002378

Latif M, Keenlyside N (2009) El Niño/Southern Oscillation response to global warming. Proc Natl Acad Sci 106:20578-20583

Li T (1997) Phase transition of the El Niño-Southern Oscillation: a stationary SST mode. J Atmos Sci 54:2872-2887

Li Y, Li J-P, Zhang W, Zhao X, Xie F, Zheng F (2015) Ocean dynamical processes associated with the tropical Pacific cold tongue mode. J Geophys Res Oceans 120:6419-6435. https://doi. org/10.1002/2015jc010814

Li Y, Li JP, Zhang W, Chen Q, Feng J, Zheng F, Wang W, Zhou X (2017) Impacts of the Tropical Pacific cold tongue mode on ENSO diversity under global warming. J Geophys Res Oceans 122:8524 8542. https://doi.org/10.1002/2017jc013052

Liu Z (2002) A simple model study of ENSO suppression by external periodic forcing. J Clim 15:1088-1098. https://doi. org/10.1175/1520-0442(2002)015\%3C1088:asmsoe\%3E2.0.co;2

Liu Z, Kutzbach J, Wu L (2000) Modeling climate shift of El Niño variability in the Holocene. Geophys Res Lett 27:2265-2268. https://doi.org/10.1029/2000gl011452

Liu Z, Lu Z, Wen X, Otto-Bliesner BL, Timmermann A, Cobb KM (2014) Evolution and forcing mechanisms of El Niño over the past 21,000 years. Nature 515:550-553. https://doi.org/10.1038/ nature 13963

Lu Z, Liu Z, Zhu J (2016) Abrupt intensification of ENSO forced by deglacial ice-sheet retreat in CCSM3. Clim Dyn 46:1877-1891. https://doi.org/10.1007/s00382-015-2681-3

Lu Z, Liu Z, Zhu J, Cobb K (2018) A review of Paleo El Niño-Southern oscillation. Atmosphere 9:130

Luan Y, Braconnot P, Yu Y, Zheng W, Marti O (2012) Early and mid-Holocene climate in the tropical Pacific: seasonal cycle and interannual variability induced by insolation changes. Clim Past 8:1093-1108. https://doi.org/10.5194/cp-8-1093-2012

Luan Y, Braconnot P, Yu Y, Zheng W (2015) Tropical Pacific mean state and ENSO changes: sensitivity to freshwater flux and remnant ice sheets at $9.5 \mathrm{ka} \mathrm{BP}$. Clim Dyn 44:661-678. https://doi. org/10.1007/s00382-015-2467-7

Lübbecke JF, McPhaden MJ (2014) Assessing the 21st century shift in ENSO variability in terms of the Bjerknes stability index. $\mathrm{J}$ Clim 27:2577-2587. https://doi.org/10.1175/JCLI-D-13-00438.1

McGregor HV, Fischer MJ, Gagan MK, Fink D, Phipps SJ, Wong H, Woodroffe CD (2013) A weak El Niño/Southern Oscillation with delayed seasonal growth around 4300 years ago. Nat Geosci 6:949-953. https://doi.org/10.1038/ngeo1936

Neelin JD (1991) The slow sea surface temperature mode and the fastwave limit: analytic theory for tropical interannual oscillations and experiments in a hybrid coupled model. J Atmos Sci 48:584-606

Otto-Bliesner BL (1999) El Niño/La Niña and Sahel precipitation during the Middle Holocene. Geophys Res Lett 26:87-90. https://doi. org/10.1029/1998g1900236

Otto-Bliesner BL, Brady EC, Shin S-I, Liu Z, Shields C (2003) Modeling El Niño and its tropical teleconnections during the last glacial-interglacial cycle. Geophys Res Lett 30:2198. https://doi. org/10.1029/2003gl018553

Pausata FSR et al (2017) Greening of the Sahara suppressed ENSO activity during the mid-Holocene. Nat Commun 8:16020. https:// doi.org/10.1038/ncomms 16020

Philander SG (1990) El Niño, La Niña, and the Southern Oscillation. Academic Press, London, 293 pp

Rasmusson EM, Carpenter TH (1982) Variations in tropical sea surface temperature and surface wind fields associated with the southern oscillation/El Niño. Mon Weather Rev 110:354-384. https://doi. org/10.1175/1520-0493(1982)110\%3C0354:vitsst\%3E2.0.co;2

Roberts WHG, Battisti DS, Tudhope AW (2014) ENSO in the MidHolocene according to CSM and HadCM3. J Clim 27:1223-1242. https://doi.org/10.1175/JCLI-D-13-00251.1

Su J, Zhang R, Li T, Rong X, Kug J, Hong C-C (2010) Causes of the El Niño and La Niña amplitude asymmetry in the equatorial eastern Pacific. J Clim 23:605-617

Su J, Li T, Zhang R (2014) The initiation and developing mechanisms of central Pacific El Niños. J Clim 27:4473-4485

Taylor KE, Stouffer RJ, Meehl GA (2012) An overview of CMIP5 and the experiment design. Bull Am Meteorol Soc 93:485

Tian Z, Li T, Jiang D, Chen L (2017) Causes of ENSO weakening during the Mid-Holocene. J Clim 30:7049-7070. https://doi. org/10.1175/jcli-d-16-0899.1

Tian Z, Li T, Jiang D (2018) Strengthening and Westward shift of the tropical Pacific Walker circulation during the Mid-Holocene: 
PMIP simulation results. J Clim 31:2283-2298. https://doi. org/10.1175/jcli-d-16-0744.1

Timmermann A, Lorenz SJ, An S-I, Clement A, Xie S-P (2007) The effect of orbital forcing on the mean climate and variability of the tropical Pacific. J Clim 20:4147-4159. https://doi.org/10.1175/ jcli4240.1

Tudhope AW et al (2001) Variability in the El Niño-Southern Oscillation through a glacial-interglacial cycle. Science 291:1511-1517. https://doi.org/10.1126/science.1057969

Wallace JM, Gutzler DS (1981) Teleconnections in the geopotential height field during the Northern Hemisphere Winter. Mon Weather Rev 109:784-812 https://doi.org/10.1175/15200493(1981)109\%3C0784:titghf\%3E2.0.co;2

Wang YY, Luo YY, Lu J, Liu FK (2018) Changes in ENSO amplitude under climate warming and cooling. Clim Dyn. https://doi. org/10.1007/s00382-018-4224-1

White SM, Ravelo AC, Polissar PJ (2018) Dampened El Niño in the early and mid-holocene due to insolation-forced warming/deepening of the thermocline. Geophys Res Lett 45:316-326. https://doi. org/10.1002/2017GL075433
Woodroffe CD, Gagan MK (2000) Coral microatolls from the central Pacific record Late Holocene El Niño. Geophys Res Lett 27:15111514. https://doi.org/10.1029/2000g1011407

Zhang W, Jin FF (2012) Improvements in the CMIP5 simulations of ENSO-SSTA meridional width. Geophys Res Lett 39

Zhang W, Li J, Jin FF (2009) Spatial and temporal features of ENSO meridional scales. Geophys Res Lett. https://doi. org/10.1029/2009GL038672

Zhang W, Jin F-F, Zhao J-X, Li J (2013) On the bias in simulated ENSO SSTA meridional widths of CMIP3 models. J Clim 26:3173-3186

Zheng W, Braconnot P, Guilyardi E, Merkel U, Yu Y (2008) ENSO at 6 $\mathrm{ka}$ and $21 \mathrm{ka}$ from ocean-atmosphere coupled model simulations. Clim Dyn 30:745-762

Zhu J et al (2017) Reduced ENSO variability at the LGM revealed by an isotope-enabled Earth system model. Geophys Res Lett 44:2017GL073406. https://doi.org/10.1002/2017g1073406

Publisher's Note Springer Nature remains neutral with regard to jurisdictional claims in published maps and institutional affiliations. 